\title{
Precariedad regulatoria y personal interino: un futuro incierto (en todos los sentidos)
}

\author{
Regulatory precarity and interim employees: an uncertain future \\ (in every sense)
}

\author{
Lorenzo Mellado-Ruiz \\ Universidad de Almería (España) \\ ORCID: https://orcid.org/0000-0002-4034-5391 \\ Imellado@ual.es
}

\section{NOTA BIOGRÁFICA}

Catedrático de Derecho Administrativo de la Universidad de Almería. Autor de numerosas publicaciones en materia de empleo público, contratación del sector público, derecho medioambiental y energético y derecho local, entre otras líneas y ámbitos de investigación.

\section{RESUMEN}

La situación del personal temporal de las Administraciones Públicas se ha convertido en los últimos años en un problema claramente estructural. La jurisprudencia comunitaria viene reiterando la insuficiencia tanto regulatoria como de gestión a nivel interno. Y, sin embargo, la reacción legislativa ha sido mínima, ambivalente y, además, sometida a plazo de caducidad. Se analiza, así, el contenido, quizás provisional en algunos aspectos, pero esencial, del Real Decreto-Ley 14/2021, desde una perspectiva crítica, y el incierto futuro inmediato de este tipo de empleado público.

\section{PALABRAS CLAVE}

Personal interino; relación de temporalidad; situaciones de abuso; procesos de estabilización.

\begin{abstract}
The situation of temporary staff in Public Administrations has become a clearly structural problem in recent years. Community jurisprudence has reiterated both the regulatory and management insufficiency at the internal level. And yet, the legislative reaction has been minimal, ambivalent and, furthermore, subject to an expiration period. Thus, the content, perhaps provisional in some aspects, but essential, of Royal Decree-Law $14 / 2021$ is analyzed from a critical perspective, and the uncertain immediate future of this type of public employee.
\end{abstract}

\section{KEYWORDS}

Interim employees; temporary relationship; situations of abuse; stabilization processes.

\section{SUMARIO}

1. INTRODUCCIÓN: APROXIMACIÓN A LA RECIENTE JURISPRUDENCIA COMUNITARIA SOBRE EL RÉGIMEN DE LOS TRABAJADORES TEMPORALES EN LAADMINISTRACIÓN PÚBLICA. 2. UNA SOLUCIÓN DE URGENCIA: EL REAL DECRETO-LEY 14/2021, DE 6 DE JULIO, DE MEDIDAS URGENTES 
DA. Nueva Época - N. 8, diciembre 2021 - ISSN: 1989-8983 - DOI: https://doi.org/10.24965/da.i8.11026 - [Págs. 92-114]

Precariedad regulatoria y personal interino: un futuro incierto (en todos los sentidos)

Lorenzo Mellado-Ruiz

PARA LA REDUCCIÓN DE LA TEMPORALIDAD EN EL EMPLEO PÚBLICO. 2.1. CARACTERIZACIÓN Y OBJETIVOS. 2.2. PREVISIONES REGULATORIAS O PRO FUTURO: EL PERSONAL FUNCIONARIO INTERINO ES, NECESARIAMENTE, PERSONAL TEMPORAL. 2.2.1. Premisa: reducir la «temporalidad» apostando por la «temporalidad» (pero el problema no es la flexibilidad o contingencia del empleo público, sino su abuso irregular). 2.2.2. Régimen jurídico. 2.2.3. Acotamiento positivo de los límites temporales de nombramiento. 2.2.4. Principios y objetivos de los sistemas de selección. 2.2.5. Objetivación de las causas de terminación de la relación interina. 2.2.6. Los funcionarios interinos siguen sin tener un «estatuto» propio. 2.3. RESPONSABILIDAD DE LA ADMINISTRACIÓN EN LOS CASOS DE ABUSO DE LA RELACIÓN DE TEMPORALIDAD. 2.3.1. Invalidez absoluta de las actuaciones de abuso. 2.3.2. Compensaciones económicas. 2.3.3. Otras proyecciones del principio de responsabilidad. 2.4. PREVISIONES INMEDIATAS O «PRO LEGISLATURA»: AMPLIACIÓN DE LOS PROCESOS DE ESTABILIZACIÓN DEL EMPLEO TEMPORAL. 2.4.1. Nuevo -y agilizado- proceso de estabilización: el objetivo del $8 \%$. 2.4.2. Sistema de selección preferente: concurso-oposición. 2.4.3. Compensaciones económicas. 2.4.4. Régimen transitorio de los procesos selectivos ya convocados. 2.5. MEDIDAS ESTRATÉGICAS (E INCONCRETAS). 2.6. OTRAS PREVISIONES COMPLEMENTARIAS. 3. FUTURO INMEDIATO PREVISIBLE Y VALORACIÓN CONJUNTA DEL PROCESO: ¿SE HA AVANZADO EN LA ADOPCIÓN DE MEDIDAS EFICACES, PROPORCIONADAS Y DISUASORIAS DE LA EXCESIVA TEMPORALIDAD EN EL EMPLEO PÚBLICO? REFERENCIAS BIBLIOGRÁFICAS.

\section{INTRODUCCIÓN: APROXIMACIÓN A LA RECIENTE JURISPRUDENCIA COMUNITARIA SOBRE EL RÉGIMEN DE LOS TRABAJADORES TEMPORALES EN LA ADMINISTRACIÓN PÚBLICA}

La compleja situación -y regulación- del personal interino o temporal en nuestro ordenamiento jurídico se ha convertido, en los últimos meses, en noticia ${ }^{1}$. No, obviamente, por la consecución de una solución equilibrada entre su situación de precariedad y en muchos casos fraude -o abuso-, o al menos de «desnaturalización» consciente de su propia naturaleza jurídica, y el respeto de los principios básicos constitucionales sobre la materia. Ni tampoco por la «inteligencia» de las medidas normativas implantadas ${ }^{2}$, ante una realidad difícilmente asumible ${ }^{3}$. Hemos asistido, así, muy al contrario, a una sucesión de propuestas regulatorias y a una solución final de emergencia que no parece haber contentado a nadie, en un oscilante y crispado escenario además de presiones de los diferentes grupos de intereses implicados ${ }^{4}$. Pero quizás haya sido la penúltima etapa de un proceso, en realidad, de «hipocresía institucionalizada» ${ }^{5}$, que, no es descartable, puede repetirse en breve ${ }^{6}$. Ya decía Voltaire que no es la Historia la que se repite, sino los hombres -y sus errores, cabría añadir-. La cuestión enlaza, no obstante, con una previa jurisprudencia a nivel comunitario no sólo de progresiva aproximación entre el personal temporal y el personal indefinido ${ }^{7}$, sino de reconocimiento de la anormalidad de las situaciones de cobertura transitoria de puestos artificialmente sostenidas en el tiempo.

1 Como se ha dicho, «la repercusión social y mediática de la reciente doctrina del TJUE sobre la contratación temporal en nuestro país es alta debido, principalmente, a que la tasa de temporalidad en España es muy elevada, y a que, por tanto, la doctrina europea podría afectar a un considerable número de trabajadores», Marín Alonso (2017).

2 Regulación de transposición de las exigencias comunitarias a las relaciones de empleo sometidas al Derecho Administrativo demandada por la doctrina desde hace tiempo, vid., por ejemplo, Campos Daroca (2017, p. 37 y ss).

3 Como dice el propio RDLey 14/2021, de 6 de julio, de medidas urgentes para la reducción de la temporalidad en el empleo público, que más adelante se analiza en detalle, la tasa de temporalidad registrada actualmente en el empleo público es ya superior a la registrada en el sector privado. Esta situación, al margen de la propia afección personal y colectiva de los trabajadores afectados, por la inestabilidad de su relación, la falta de seguridad jurídica y certidumbre sobre su futuro y la especial vulnerabilidad existente, conlleva no sólo el cuestionamiento fáctico del propio modelo constitucional de función pública, sino de la misma capacidad estructural de las Administraciones públicas para una adecuada prestación de los servicios públicos, impidiendo una adecuada racionalización de los sistemas de acceso, provisión y gestión de los recursos humanos y un desarrollo con calidad de las actividades prestacionales.

4 Quizás, como se ha dicho, por el recurrente «síndrome del horror al conflicto» propio, en ciertos ámbitos especialmente sensibles como la gestión del personal, de la Administración y de las mismas autoridades gubernamentales de dirección de la misma (Cantero Martínez, 2021).

5 Fuentetaja Pastor (2020c, p. 204).

6 En este sentido, Moro Tella (2021).

7 El problema no estriba, como se ha dicho, en que las novedades y cambios en esta materia deriven, indirectamente, de la jurisprudencia o la normativa comunitaria, lo cual es por lo demás normal en muchos de los ámbitos jurídico-públicos en la actualidad, sino en el denunciable hecho de que su «afrontamiento» normativo interno obedezca a estos «estímulos», y no al debate público (parlamentario) correspondiente ante situaciones de modificación, cambio o superación de la regulación de la misma, vid. Sánchez Morón (2019, p. 226). 
Nuestro modelo de empleo público, efectivamente, y desde la conocida dicotomía básica entre personal funcionario de carrera y personal funcionario temporal (interinos), se ha visto sacudido en los últimos tiempos por una continuada jurisprudencia comunitaria de progresiva equiparación (igualdad de trato y no discriminación) entre ambas figuras ${ }^{8}$, que ha culminado con la STJUE de 19 de marzo de 2020 (asuntos acumulados C-103/18 y C-429/18) ${ }^{9}$.

Nos centramos en este último pronunciamiento, al constituir la decisión más avanzada en este proceso, pero, a la vez, la más problemática en cuanto a su traslación efectiva a nivel interno ${ }^{10}$ (confirmada no obstante después en diferentes pronunciamientos, el último de ellos la STJUE de 3 de junio de 2021, as. C-726/19).

La Sentencia versa sobre la interpretación de la cláusula $5 .^{a}$ del Acuerdo marco sobre el trabajo de duración determinada, de 18 de marzo de 1999, como anexo a la Directiva 1999/79/CE, del Consejo, de 28 de junio, relativa al Acuerdo Marco de la CES, la UNICE y el CEEP sobre el trabajo de duración determinada ${ }^{11}$, y en concreto sobre las consecuencias para la relación temporal de empleo del propio incumplimiento del empleador, en nuestro caso las Administraciones Públicas, en su obligación de organización y provisión de los procesos selectivos correspondientes para la cobertura de las plazas vacantes. Este Acuerdo marco entron$\mathrm{ca}$, en el fondo, con el derecho fundamental a la no discriminación que reconocen obviamente la generalidad de los textos constitucionales europeos, pero concretándolo en relación con los trabajadores temporales.

Caber recordar, aun sucintamente, que esta Directiva, que es aplicable al personal laboral y funcionarial del sector público, prohíbe que el personal temporal sea destinado a desempeñar de modo permanente y estable, por la propia naturaleza de su relación de empleo, funciones propias del personal fijo.

La Directiva es aplicable a todo el empleo público en España porque, entre otras razones, el Derecho de la Unión Europea, como sucede en otros muchos ámbitos, no distingue entre las categorías nacionales -internas- de empleo público (STS de 22 de octubre de 2012, rec. 5303/2011). En concreto, el Acuerdo Marco establece principios generales y condiciones mínimas para la contratación temporal o de duración determinada del personal sometido a régimen jurídico-privado o laboral y a régimen jurídico-público o administrativo, desplegando su eficacia en todas las materias en que la naturaleza temporal del vínculo no sea decisiva para el establecimiento de diferencias entre trabajadores indefinidos y temporales ${ }^{12}$.

Objetivamente, por tanto, la utilización por parte de un empleador (o una Administración pública) de personal temporal para cubrir necesidades permanentes constituiría un abuso o fraude -tanto desde un punto de vista organizativo/institucional como económico/retributivo- y una violación inmediata del propio Derecho comunitario, desde el principio basal de la igualdad de trato de los trabajadores, temporales o definitivos, que ocupan un mismo puesto de trabajo y realizan unas mismas funciones (públicas).

Técnicamente, y a mi juicio, es dudoso afirmar que la existencia -innegable por otro lado-, de los posibles abusos en el caso del personal interino estuviera «amparada» en -o derivase directamente de- la propia normativa aplicable ${ }^{13}$ (singularmente, y como se sabe, en el Real Decreto-Legislativo 5/2015, de 30

8 Vid. así, por ejemplo, Mateos Martínez (2020, p. 389).

9 Lo que ha conducido, como se sabe, entre otras consecuencias, a una progresiva dilución de las barreras regulatorio-institucionales entre el ordenamiento jurídico laboral y el administrativo -y sus respectivos órdenes jurisdiccionales-, a través, por ejemplo, de la propuestas jurisprudenciales de traslado automático de la figura del personal laboral indefinido del derecho laboral al ámbito de las relaciones funcionariales y estatutarias. Vid., por ejemplo, Castillo Blanco (1995, pp. 187-218).

10 Así, Sánchez Quiñones (2020).

11 Los dos objetivos básicos de esta Directiva, interrelacionados además entre sí, son: i) el establecimiento de los principios generales y condiciones mínimas para que los contratos de trabajo de duración determinada y las relaciones laborales temporales tengan un mayor nivel de garantías, en virtud del principio general de no discriminación -de trato- basada en la -mera- duración de la relación laboral; y ii) la consagración de reglas directivas para evitar abusos en la utilización de este tipo de vínculos temporales o precarios, desde la priorización general de los contratos indefinidos. En definitiva, se trataría de positivizar una doble equivalencia por lo demás obvia: i) que los contratos de duración determinada -y las relaciones temporales de empleo- deben destinarse a cubrir necesidades temporales, coyunturales o especiales y ii) que, desde su «propia naturaleza», pero no equivalencia sustancial al resto de relaciones, se garantice un trato no discriminatorio respecto de los indefinidos comparables. En definitiva, existiría a nivel comunitario una prohibición general de tratar de manera menos favorable, en sus condiciones de trabajo, a los trabajadores con un contrato de duración determinada que a los trabajadores fijos o permanentes comparables, por el mero hecho de tener un contrato de duración determinada, a menos que tal diferenciación se justificara o deviniera de razones claramente objetivas (donde no habría ya entonces trato discriminatorio sino soluciones -previsiones-distintas sobre supuestos distintos).

12 Marín Alonso (2017) y Suárez Corujo (2017, pp. 153-185).

13 Quizás sea más apropiado hablar, efectivamente, de abuso o irregularidad fáctica, más que de fraude o ilegalidad de la actuación de la Administración en estos casos. Porque realmente no hay una actuación carente de «legitimidad normativa» por completo. Podría haber, más bien, un abuso o interpretación interesada de las previsiones normativas aplicables. Por ello, el fraude de ley en la temporalidad se reconduciría a situaciones que, amparadas inicialmente en la Ley, dejan posteriormente de estarlo o que excepcionalmente se permiten o toleran pese a carecerse del título o habilitación normativa correspondiente, es decir, del hecho habilitante 
de octubre, por el que se aprueba el Texto Refundido del Estatuto Básico del Empleado Público, en adelante TREBEP ${ }^{14}$ ), pero sí es cierto que esta importante Sentencia establece, en sus apartados 71 y 75 , que los abusos contrarios a la Directiva 1999/70/CE se producen cuando se destina a empleados públicos temporales a atender necesidades que, de hecho, no son provisionales, esporádicas, puntuales, excepcionales 0 coyunturales, sino que son ordinarias, estables y permanentes, cubriendo el empleador con personal temporal sus necesidades estructurales en materia de personal, al no disponer de suficientes funcionarios fijos o de carrera. La patología no sería, por tanto, la existencia de las relaciones temporales de empleo público sino su utilización inadecuada o fraudulenta. Y ésta, a su vez, derivaría o de decisiones directamente abusivas, y por tanto directamente contrarias a las exigencias normativas correspondientes, o de decisiones, de carácter quizás más mediato, pero con las mismas consecuencias, derivadas de la percepción de la rigidez, complejidad y lentitud de los procesos ordinarios de selección.

En nuestro país, además, y de forma quizás más intensa que en otros, esta práctica (de lo que podría denominarse como «interinidad estructural» ${ }^{15} \mathrm{O}$ "de hecho» ${ }^{16}$ ), ya conocida, se ha visto incrementada en los últimos años a través de las decisiones políticas de control del gasto público, equilibrio económico-financiero de los entes públicos y aplicación de las tasas de reposición ${ }^{17}$, que han venido incluso a "desnaturalizar» en el fondo la propia estructura de nuestro sistema de empleo público, con el surgimiento -práctico y jurisprudencial- de la figura de los -mal llamados- «interinos de larga duración» ${ }^{18}$, o -por imitación- «indefinidos no fijos de Derecho Administrativo» ${ }^{19}$.

Existiría abuso, pues, como concepto estrictamente comunitario ${ }^{20}$, cuando se hubiese utilizado personal público temporal para cubrir un déficit estructural.

El debate -jurídico- planteado, que se plasma en la actual conflictividad en torno a la figura de los interinos temporales, resulta claro: de un lado, el Derecho comunitario exige que los Estados miembros adopten medidas adecuadas para prevenir y, en su caso, sancionar estos posibles abusos derivados de la utilización de sucesivos contratos o relaciones laborales de duración determinada y, en el caso del personal interino, de la situación continuada de precariedad (cronificación del empleo de duración determinada), realmente no imputable al mismo, a pesar de la ocupación y desempeño de puestos de trabajo en principio reservados para funcionarios; de otro, nuestro Derecho interno en materia de empleo público, donde obviamente existe temporalidad y precariedad, pero no encadenamiento sucesivo y abusivo de contratos (laborales) temporales por parte de un empresario ${ }^{21}$, y donde parece conveniente modular las exigencias derivadas de una interpretación estricta de esta Sentencia a la luz de los ineluctables principios constitucionales de mérito y capacidad en el acceso (definitivo) a las funciones y cargos públicos (art. 23.2 CE) y de las propias posibilidades de actuación/revisión de la Administración ${ }^{22}$.

previsto en la propia norma, vid. Cabrera Rodríguez (2020, p. 414). Como ha dicho en este sentido Fuentetaja Pastor (2020a, p. 89), «la duración excesiva o abusiva de la relación de interinidad es consecuencia no sólo de la vulneración de las normas encaminadas a prevenirlas sino también de técnicas de regulación, de interpretación y de gestión informadas por el objetivo aparentemente paradójico de garantizar una mayor estabilidad y duración de las interinidades funcionariales».

14 A pesar de las indudables deficiencias -e insuficiencias- de la regulación de mínimos que contiene en relación con el personal interino, básicamente el art. 10, fundamentalmente en relación con la interpretación -y aplicación casuística- de los -tasados- presupuestos habilitantes para su utilización por parte de las Administraciones Públicas.

15 Fernández Domínguez (2020, p. 176).

16 Cabrera Rodríguez (2020, p. 408).

17 Por todos, Fuentetaja Pastor y Cantero Martínez (2012). Consideraciones «puramente económicas» que, como ha recordado recientemente el propio TJUE, no pueden justificar la inexistencia, en el Derecho nacional, de las citadas medidas para prevenir y sancionar la utilización sucesiva de contratos de trabajo de duración determinada (STJUE de 3 de junio de 2021, asunto C-726/19).

18 Cantero Martínez (2017, p. 13). Como se sabe, ya el propio TC en su Sentencia 240/1999, de 20 de diciembre, había declarado que el establecimiento de un trato diferenciado entre los diversos cuerpos y categorías de funcionarios -permanentes o temporales, incluidos los nombrados por razones de necesidad y urgencia- carecía realmente de respaldo constitucional en su proyección específica a los interinos de larga duración.

19 Fuentetaja Pastor (2020c, p. 212) y Martín Muñoz y Monereo Pérez (2021).

20 Vid., por ejemplo, Sánchez Morón (2020, p. 121 y ss.).

21 Por ello se ha señalado que no resulta de fácil aplicación la Directiva 1999/70 al ámbito de las relaciones jurídico-públicas de duración determinada, por las deficiencias regulatorias, por la inercia administrativa y por el debate judicial interno originado, vid. Fuentetaja Pastor (2020c, p. 205).

${ }_{22}$ Como sostuvo por ejemplo en este sentido la STS de 26 de septiembre de 2018 (rec. 1425/2018), la adopción de una medida de declaración de anulabilidad del acto administrativo por cese indebido de personal interino cumpliría adecuadamente las exigencias fijadas por el TJUE y el propio Acuerdo Marco de establecimiento de medidas sancionadoras por la utilización abusiva de la contratación temporal, «porque tal consecuencia es la única que, amén de ser proporcionada al propio actuar de la Administración, es igualmente lo 
Por ello, señala esta Sentencia del TJUE que «corresponde al órgano jurisdiccional nacional apreciar, con arreglo al conjunto de normas de su Derecho nacional aplicables, si la organización de procesos selectivos destinados a proveer definitivamente las plazas ocupadas con carácter provisional por empleados públicos nombrados en el marco de relaciones de servicio de duración determinada, la transformación de dichos empleados públicos en indefinidos no fijos y la concesión a estos empleados públicos de una indemnización equivalente a la abonada en caso de despido improcedente, constituyen medidas adecuadas para prevenir, y, en su caso, sancionar, los abusos derivados de la utilización de sucesivos contratos o relaciones laborales de duración determinada o medidas legales equivalentes».

En caso de utilización abusiva de las relaciones de duración determinada, por tanto, las autoridades nacionales deben adoptar las medidas proporcionadas, efectivas y disuasorias que sean necesarias para cumplir las normas del Acuerdo Marco, en tanto garantías de protección de los trabajadores afectados efectivas y equivalentes (al personal fijo), pero no se impone -inmediatamente- la obligación de transformar las relaciones por tiempo determinado en relaciones indefinidas ${ }^{23}$, resultando posible adoptar medidas distintas según el empleador corresponda al sector público o al sector privado (o, implícitamente, si la relación es de derecho laboral o de derecho administrativo) ${ }^{24}$.

De esta doctrina jurisprudencial podrían destacarse los siguientes aspectos nucleares:

1. ${ }^{\circ}$ El cumplimiento del Derecho comunitario, en su interpretación judicial, y aún desde su innegable primacía sobre el Derecho interno, debe lograrse, no obstante, desde la coherente e íntegra aplicación de nuestro sistema jurídico interno ${ }^{25}$;

2. La prevención o, en su caso, sanción del exceso de temporalidad no tiene una única respuesta (singularmente, la conversión de las relaciones temporales en indefinidas o de duración indeterminada): la solución puede pasar por la estabilización del personal temporal, por la mera indemnización económica ${ }^{26}$ o por el propio -y normal- desarrollo de los procesos selectivos correspondientes (para la cobertura de las plazas ocupadas por el personal interino). Es conveniente subrayar esta pluralidad de opciones, en un contexto de necesaria discrecionalidad decisional de cada Administración, propia de las amplias facultades de autoorganización interna y de la propia inexistencia al respecto de previsiones comunitarias únicas, precisas e incondicionadas en relación con la sanción de los abusos en la contratación temporal ${ }^{27}$;

3. - La aquiescencia o consentimiento (explícito o implícito) del personal interino en la «perpetuación» de su relación temporal de empleo no impide la aplicación de estas medidas ${ }^{28}$; y.

$4^{\circ} \quad$ Las medidas de prevención o sanción han de ser consecuencia de -o preferiblemente, habrían de evitar- situaciones de abuso de la contratación temporal por parte de la Administración. Deberían verificarse, pues, dos elementos: uno objetivo, la relación de causalidad entre la situación de

bastante efectiva y disuasoria como para garantizar la plena eficacia del Acuerdo marco», vid., así, con más profundidad, el estudio de Fondevila Antolín (2018, p. 72 y ss.).

23 Aún más, realmente el instrumento europeo citado, en caso de poder comprobar situaciones de abuso, no establece sanción específica alguna, sino que deja a los Estados la elección de los medios para alcanzar sus fines, vid. Fernández Domínguez (2020, p. 172) y Rodríguez Escanciano (2020). Sobre la imposibilidad directa de conversión del personal interino en indefinido no fijo, aplicando de forma analógica la jurisprudencia del orden social, ya se había venido pronunciado de hecho nuestro TS, por ejemplo en la anteriormente citada Sentencia de 26 de septiembre de 2018, comentada por Sánchez Morón (2019, pp. 223-238). También, Alfonso Mellado (2018, pp. 147-158).

24 Vid. Sánchez Morón (2019, p. 233). La jurisprudencia europea ya había admitido, así, que no se imponía un tratamiento uniforme de la cuestión tanto en el sector público como en el privado, a la hora de prevenir o sancionar en su caso la utilización abusiva de relaciones de trabajo de duración determinada, e incluso que, a tenor de los intereses en presencia, la medida concreta de conversión de las relaciones temporales en definitivas no se aplicara cuando se tratara de las relaciones de empleo con la Administración Pública (STJUE de 7 de julio de 2006, as. C-212-04). La reciente STJUE de 19 de marzo de 2020 vuelve a reiterar que el apartado primero de la cláusula 5 de la Directiva 1999/70/CE no es incondicional ni suficientemente preciso como para que un particular pueda invocarlo ante un juez nacional.

25 Sobre las «medidas» existentes a nivel interno para la lucha contra el abuso de la temporalidad del empleo público, puede verse por ejemplo Arrieta Idiakez (2020).

26 Sobre esta posibilidad puede verse, por ejemplo, Monereo Pérez y Ortega Lozano (2019).

${ }_{27}$ Como bien se ha señalado la respecto, la propia estructura interna de la Directiva 1999/70 exige que la transformación de las relaciones temporales en indefinidas deba ser consecuencia del derecho interno, bien porque este haya establecido tal medida específicamente como ejecución de la Directiva, bien porque la normativa nacional anude esa consecuencia a situaciones estrictamente internas y, por semejanza de situación, se pueda extender a la situación regulada en el derecho europeo, Fuentetaja Pastor (2020c, p. 206). Es verdad no obstante, y de ahí la falta de cierre del debate realmente, la propia desconfianza del TJUE a la hora de cotejar la adecuación del ordenamiento interno a las exigencias comunitarias, tanto desde la perspectiva del «recordatorio» de opciones como desde la exigencia de que las medidas a tomar a nivel interno, sean eficaces, efectivas y proporcionadas, vid. en este sentido Sánchez Quiñones (2020).

28 Apartado 114 STJUE de 19 de marzo de 2020. 
precariedad y la actividad administrativa; y otro subjetivo, la intención de abusar, aprovecharse o beneficiarse la Administración de tales situaciones.

Ahora bien, también es verdad que la autonomía institucional interna en la materialización de las exigencias comunitarias, máxime, como decimos, en un ámbito de amplia discrecionalidad administrativa (de organización y gestión de personal), queda limitada por el conocido principio del efecto útil del Derecho comunitario, y de la efectiva consecución, aún con libertad de medios, de los objetivos comunes establecidos vía uniformización normativa ${ }^{29}$. A ello hay que sumar el hecho de que los Estados no son completamente libres para ello, pues deben garantizar, por un lado, un nivel de ejecución semejante al del derecho interno (principio de equivalencia) y, por otro, la eficacia del derecho europeo independientemente de la regulación ejecutiva del derecho interno (principio de efectividad) ${ }^{30}$.

En este caso, esas diferentes opciones a disposición de la Administración (su margen de discrecionalidad) quedan limitadas, en tanto que las medidas sancionadoras del abuso de la temporalidad deben ser, según la jurisprudencia comunitaria, «efectivas, disuasorias y proporcionadas» ${ }^{31}$.

La Directiva 1999/70/CE impone, pues, no sólo un resarcimiento efectivo y adecuado (al empleado precario víctima del abuso), sino además un cierto efecto disuasorio o desincentivador (para el empleador o Administración) en la continuación o reiteración de estas conductas. La asunción íntegra y efectiva de ambas dimensiones parecería exigir realmente medidas más contundentes que la mera estabilización o consolidación del empleo o el posible resarcimiento por daños y perjuicios (en sede judicial). A mi juicio, por ello, la verdadera «disuasión» de futuras conductas de abuso no habría de pasar por fórmulas «sancionadoras» (teniendo en cuenta que hablamos de la Administración pública ${ }^{32}$ ), sino por una auténtica, efectiva y adecuada modificación legal que asegure el cumplimiento, temporal y sustantivo, de los diferentes procesos selectivos, en el marco de procesos realmente estratégicos de racionalización del empleo público y sobre la base de los principios constitucionales de mérito y capacidad ${ }^{33}$.

\section{UNA SOLUCIÓN DE URGENCIA: EL REAL DECRETO-LEY 14/2021, DE 6 DE JULIO, DE MEDIDAS URGENTES PARA LA REDUCCIÓN DE LA TEMPORALIDAD EN EL EMPLEO PÚBLICO}

\subsection{Caracterización y objetivos}

Obviamente, dicha modificación o adaptación legislativa integral y consensuada, no se ha producido. Frente a la racionalización del modelo y la búsqueda de soluciones equilibradas entre el respeto del Derecho comunitario y la observancia de los principios constitucionales, se ha aprobado una mínima regulación de urgencia (desde la dimensión sustantiva), que, además, se encuentra en la actualidad, de nuevo en virtud de razones extrajurídicas, pendiente a su vez de modificación.

Como por desgracia viene siendo habitual, en la desproporcionada -y literalmente reiterativa- exposición de motivos de esta norma se realiza, bien que certeramente, una adecuada descripción del problema y sus antecedentes.

Es evidente, y se parte de su reconocimiento expreso, de que la mejor gestión del empleo al servicio de las distintas Administraciones Públicas exige disponer de políticas coherentes y racionales de dotación de

29 Así lo ha vuelto a reconocer recientemente en esta materia la STJUE de 11 de febrero de 2021 (asunto C-760/18).

30 Fuentetaja Pastor (2020c, pp. 205-206).

31 El resultado es ciertamente complejo: «el TJUE se rinde a la evidencia y deja en manos de las autoridades nacionales, también -y especialmente llegado el caso- las judiciales, la tarea de hallar solución al problema, a partir de la debida aplicación de una normativa interna que reconoce no ajustada a los contenidos de la Directiva y Acuerdo Marco, pero que ha de interpretar con arreglo al Derecho de la Unión, sin desplazarla, en una suerte de cuadratura del círculo. Complicada solución sin duda», Carbonero Redondo (2020).

32 Vid., así, Barrachina Andrés (2020, p. 85 y ss.). Además, dice la autora, «es una sanción de la que resultaría especialmente beneficiada "la víctima", el funcionario que ha sufrido el abuso, siendo inconcebible en nuestro Derecho que la sanción altere el estatus jurídico de las víctimas».

33 En este sentido se ha afirmado, a mi juicio con razón, que la propia jurisprudencia comunitaria no impone, exige o recomienda una solución consistente en la estabilización automática a través del atajo que proporciona la utilización de un camino equivocado. No cabe, así, la conversión de una relación temporal claramente abusiva en otra de personal fijo a través de sentencia. Se impone una solución normativa específica, puesto que se considera que «el marco normativo existente en España no proporciona una respuesta adecuada a la gravedad del problema» (y todo ello con independencia del propio impulso de los procesos selectivos correspondientes, aún con una -posible y oportuna- reconsideración del tipo y desarrollo de las pruebas y de la valoración de los servicios prestados), Fernández Domínguez (2020, p. 176). 
efectivos de carácter permanente, en tanto principal activo de la acción pública, que cubran las necesidades reales de los servicios y limiten la temporalidad a la atención de necesidades de carácter estrictamente coyuntural. Sin embargo, la tasa de temporalidad no ha hecho sino aumentar desde hace décadas en nuestro país. Las razones son variadas: de tipo presupuestario, por una insuficiente planificación estratégica en la ordenación del empleo público y la falta de regularidad de las convocatorias para la cobertura de vacantes con carácter definitivo, por la lentitud y complejidad en ocasiones de los procesos selectivos, etc ${ }^{34}$. $\mathrm{Y}$ esta anomalía ha desembocado en la reseñada jurisprudencia comunitaria que, si bien no impone la transformación automática de las relaciones temporales de servicio en permanentes ${ }^{35}$, sí que exige que las «autoridades españolas instauren medidas efectivas que disuadan y, en su caso, sancionen de forma clara el abuso de la temporalidad, y que las diferencias en el régimen jurídico del personal temporal y del fijo se basen únicamente en razones objetivas que puedan demostrar la necesidad de estas diferencias para lograr su fin ${ }^{36}$.

Se asume, pues, la necesidad de una acción interna para atajar definitivamente el problema. Y ello, asegurando la efectividad y claridad de las medidas, y no su simple aprobación (formal), en la consecución de los dos objetivos clave: la disuasión -futura- del abuso de la temporalidad y la sanción -presente- de las prácticas irregulares cometidas. La regulación es imprescindible; la reacción sancionadora -que entiendo no cabe identificar sin más con la potestad sancionadora administrativa al hablarse realmente de «medidas de sanción»-, contingente, dependiendo obviamente de la comisión -adecuadamente tipificada- de las infracciones correspondientes y su adopción -en sede judicial o no- o, al menos, de la incursión en algún tipo o modalidad de responsabilidad. Pero además, y como escenario mayor, del que el fraude en la temporalidad es sólo una proyección específica, se establece que las diferencias en el régimen jurídico entre el personal temporal y el fijo -mejor, permanente- sólo pueden basarse en razones objetivas, suficientes y proporcionadas al fin -regulatorio- concreto. Estos parámetros en la utilización de contratos de trabajo de duración determinada persiguen, en definitiva, la evitación de los abusos.

El objetivo de la reforma (sic) es, en fín, situar la tasa de temporalidad estructural (sic) por debajo del $8 \%$ en el conjunto de las Administraciones públicas españolas ${ }^{37}$, actuando en tres dimensiones, que se desarrollan a continuación: i) adopción de medidas inmediatas para remedir la elevada temporalidad existente; ii) articulación de medidas eficaces para prevenir y sancionar el abuso y el fraude en la temporalidad a futuro y iii) potenciación de la adopción de herramientas y una cultura de la planificación para una mejor gestión de los recursos humanos ${ }^{38}$.

\subsection{Previsiones regulatorias o pro futuro: el personal funcionario interino es, necesariamente, personal temporal}

\subsubsection{Premisa: reducir la "temporalidad» apostando por la «temporalidad» (pero el problema no es la flexibilidad o contingencia del empleo público, sino su abuso irregular)}

Esta norma -que no es una reforma- parte de una idea y un propósito claros: reforzar o asegurar la noción de temporalidad, y, con ello, aclarar la propia naturaleza jurídica del personal interino.

34 Vid. en este sentido, la certera descripción que realiza Sánchez Morón (2020, p. 11 y ss.).

35 Lo cual iría, en nuestro ordenamiento jurídico, y en el caso del personal funcionario temporal, contra los propios principios constitucionales de igualdad en el acceso a la función pública (arts. 14 y $23.2 \mathrm{CE}$ ).

36 En la línea establecida en su día por la STJUE de 13 de septiembre de 2007 (asunto Del Cerro Alonso), sobre la irregularidad, por vulneración del propio principio de igualdad, de los denominados nombramientos o contratos «inusualmente largos». Más recientemente, en el mismo sentido, la STS de 322/2019, de 24 de abril y también en Casas Baamonde (2019), Casas Baamonde y Ángel Quiroga (2020) y Terradillos Ormaetxea (2019, pp. 69-94).

37 Sí puede hablarse no obstante, en un cierto sentido, de la función institucional del personal interino. Es decir, el funcionario interino realmente, a pesar de la transitoriedad de su vínculo, es funcionario, y por ello hace efectiva la opción constitucional preferencial por las relaciones funcionariales en la Administración en lo que respecta a las necesidades temporales. «La interinidad paradójicamente es una realidad estructural en las Administraciones en el sentido de que siempre habrá necesidades temporales. [...]. Pero esta estructuralidad de la temporalidad en la Administración no significa que la temporalidad de los interinos deba o pueda ser estructural: organizativamente siempre habrá necesidades temporales, pero subjetivamente eso no implica que pueda haber relaciones temporales continuas», Fuentetaja Pastor (2020b, p. 45).

38 Aunque es verdad que en el articulado objeto de la reforma no se hace una mención específica a la cuestión, lo cierto es que estas referencias introductorias y la propia interpretación conjunta de la norma parecen dar a entender que las medidas de lucha contra la temporalidad del empleo público aprobadas no serían aplicables al personal temporal de entidades del sector público no Administración pública. Y este "olvido», más allá de la forzada interpretación de los preceptos relativos a la exigencia de responsabilidad al empleador público o la indemnización específica prevista para el personal laboral temporal por el incumplimiento de plazos máximos, resulta cuestionable, vid. Esteban Miguel (2021). 
Se quiere con ello, quizás de forma paradójica, evitar no la temporalidad, sino su abuso o fraude ${ }^{39}$. Se entiende que la mejor perfilación positiva de la figura contribuirá, a la larga, a la evitación de situaciones de abuso, mala interpretación o inadecuada aplicación de la misma ${ }^{40}$.

El personal interino es, y ha se seguir siendo, personal temporal, necesariamente temporal ${ }^{41}$. Su utilización, pues, para funciones estructurales, indefinidas o permanentes constituye una fraudulenta utilización organizativa de la institución.

En este punto, pues, y con carácter preliminar, la nueva regulación no modifica sustancialmente la naturaleza jurídica del personal temporal. Más bien al contrario. La nueva redacción del art. 10.1 TREBEP mantiene la caracterización del personal funcionario interino, como aquellos empleados que por razones expresamente justificadas de necesidad y urgencia, es decir en situaciones de cierta «excepcionalidad», son nombrados para el desempeño de funciones propias de los funcionarios de carrera, cuando se dé alguna de las circunstancias que tasa a continuación, pero, y se introduce expresamente ahora, con carácter necesariamente «temporal». No hay, pues, un nombramiento alternativo -o similar- para el ejercicio de funciones propias del personal indefinido, sino un nombramiento «temporal» para cubrir, por causas específicas y por tiempo limitado, dichas funciones. La relación ordinaria de empleo público es, pues, la estatutaria propia del funcionario de carrera.

Al margen de la finalidad -inmediata- de la evitación de las situaciones de abuso, fraude o utilización irregular de la figura, parece querer incidirse también en este punto en la diferenciación material de la naturaleza jurídica de los dos tipos de funcionarios de nuestro ordenamiento, precisamente para justificar su diferente tratamiento jurídico (razones objetivas de trato desigual) sin incurrir en discriminación, sobre todo desde el punto de vista del carácter -indefinido o no/ordinario o excepcional- del vínculo jurídico con la Administración.

Aunque las funciones públicas desempeñadas sean las mismas, no lo es la relación de servicio o empleo que las fundamenta y encubre. Los funcionarios interinos son, necesariamente, personal temporal, precario o transitorio. Negativamente, esto significa que no tienen, en su integridad, los mismos derechos y deberes que los funcionarios de carrera. Pero, positivamente, también significa, que no puede abusarse de su condición -naturalmente- temporal, y utilizar a este tipo de personal para funciones permanentes, estructurales o continuadas en el tiempo. No se trata sólo de un abuso o aprovechamiento por parte de la Administración empleadora, sino de un auténtico desconocimiento o elusión de su excepcional naturaleza jurídica, acarreando entonces la existencia de discriminación al fundarse el tratamiento diferente en la mera extensión del vínculo de empleo.

Por eso, el problema no es la existencia de figuras de servicio público de naturaleza o vínculo temporal. Razones no sólo de agilidad, adaptabilidad y diversificación organizativa pueden justificarlas sin duda ${ }^{42}$. Hoy en día además, con más razón, desde la perspectiva dinámica de una Administración más flexible, técnica, racional y susceptible de adaptarse, en su funcionamiento diario, a las nuevas necesidades o exigencias ciudadanas ${ }^{43}$. El problema es su abuso o fraude, la «desnaturalización», buscada directamente o tolerada implícitamente, de la naturaleza necesariamente limitada en el tiempo de los servicios -excepcionales- de este tipo de personal.

\subsubsection{Régimen jurídico}

Tampoco cambia sustancialmente el -inexistente- régimen jurídico del personal funcionario interino. La nueva redacción del art. 10.6 TREBEP sigue destilando ambigüedad y mero reenvío. Al personal funciona-

39 Por ello, muy gráficamente se ha criticado que es difícil solucionar un abuso con más abuso ...

40 Evidentemente, no supone la regulación de todo el personal interino existente, con una solución universal y directa de la problemática. Como aclara la D. T. 2. a, «las previsiones contenidas en el art. 1 serán de aplicación únicamente respecto del personal temporal nombrado o contratado con posterioridad a su entrada en vigor». Curiosamente, alguna importante construcción doctrinal de Derecho público comparado se ha basado precisamente en la concepción de -casi- todo el Derecho Administrativo como Derecho de prevención del «abuso de poder», vid. Wade (2014).

41 «La relación de empleo del funcionario interino es siempre de naturaleza temporal o transitoria, sea cual sea su duración efectiva. [...]. Quiere ello decir que dicha relación está sujeta en todo caso a un término o a una condición resolutoria y que el interino debe ser cesado cuando se cumpla uno u otra, sin que la Administración empleadora pueda dejar legalmente de aplicar las causas de cese, ya que no goza de ningún margen de discrecionalidad al efecto», Sánchez Mórón (2020, p. 24).

42 La necesidad de prestaciones o servicios de naturaleza temporal se ha puesto en relación, además, con las nuevas necesidades que previsiblemente tendrá la Administración en los próximos años: complejidad, alta cualificación y profesionalización de las competencias y funciones, automatización, reestructuración de plantillas y digitalización masiva de los procedimientos, organización y gestión de las tareas por proyectos y objetivos, más allá de la inflexibilidad horaria, etc., Cantero Martínez (2021).

43 Así, Castillo Blanco (2020). 
rio interino le sigue siendo aplicable «el régimen general del personal funcionario de carrera en cuanto sea adecuado a la naturaleza de su condición temporal» ${ }^{44}$. No ayuda el mantenimiento de esta equivalencia, al menos en términos «generales» (que el TREBEP no distingue ni delimita, por cierto), a la diferenciación de la naturaleza jurídico-sustantiva de ambos tipos de personal, que es lo que justificaría-objetivamente- un trato diferente. Como insiste el TJUE, la naturaleza temporal de la relación de servicios no es, en sí misma, una razón objetiva suficiente para permitir un trato diferenciado entre funcionarios interinos y funcionarios de carrera $^{45}$. Es verdad que, como se sabe, existe hoy una aproximación interpretativa intensa, y constante, pero también que se trata de empleados públicos «diferentes», demandantes seguramente de un régimen jurídico respectivo. En cualquier caso, sí se aclara que la aplicación analógica del régimen de los funcionarios de carrera sólo lo será en lo que sea adecuado (¿?) a la naturaleza de su condición «temporal». Y, además, «al carácter extraordinario y urgente de su nombramiento». En cierta forma con carácter reiterativo, pero se pretende constatar formal y positivamente la naturaleza «especial» de la relación de interinidad, tanto desde el punto de vista temporal como sustantivo/habilitante. A falta de regímenes -completos- respectivos, se insiste en la naturaleza específica, como criterio objetivo de diferenciación, y con el límite último de la imposibilidad de aplicación analógica, consecuentemente, de «aquellos derechos inherentes a la condición de funcionario de carrera». Como se ha visto más arriba, según el TJUE el principio de no discriminación no se predica respecto de trabajadores pertenecientes a categorías distintas, que tienen, o deberían tener, un régimen jurídico igualmente distinto ${ }^{46}$.

A mi juicio, el problema es de fondo. La dificultad del acomodamiento de la regulación de nuestro ordenamiento jurídico sobre el personal interino a las exigencias comunitarias deriva no sólo de la falta de regulación específica y especial -que singularizaría sus funciones, o al menos el régimen de su desempeño, dada la prioritaria naturaleza objetiva de su relación estatutaria-, sino de su misma configuración institucional ${ }^{47}$. El funcionario interino es, así, sencillamente, el que temporalmente desempeña las funciones de un funcionario de carrera (que, de por sí, son en principio indefinidas). No hay diferenciación sustantiva o material, ni diferentes «condiciones de trabajo», en la terminología del TJUE ${ }^{48}$, sino sólo y únicamente el carácter temporal del nombramiento ${ }^{49}$. Resulta complicado, por ello, si no imposible, discernir o determinar qué aspectos o elementos de la relación de empleo son objetivamente diferentes - para justificar un trato igualmente diferente-.

\subsubsection{Acotamiento positivo de los límites temporales de nombramiento}

En cualquier caso, la naturaleza temporal del vínculo de interinidad también se explicita, a continuación, en la nueva regulación de las causas de nombramiento -y sus correspondientes condiciones resolutorias-, ya de por sí intrínsecamente temporales, y en la delimitación del plazo máximo de duración del mismo.

Las únicas cuatro circunstancias que pueden legitimar el nombramiento -necesario y urgente, como auténticos presupuestos habilitantes de necesaria motivación ${ }^{50}$ - de funcionarios interinos son las siguientes:

a) La existencia de plazas vacantes, cuando no sea posible su cobertura por funcionarios de carrera, y añadiéndose ahora, «por un máximo de tres años». La interinidad por vacante exige, pues, que dicha vacante o vacantes no puedan ser cubiertas por funcionarios de carrera, pero esta imposibilidad no es «subjetiva»: la Administración no tiene libertad para decidir cómo se cubre una plaza correspon-

44 Vid. Fuentetaja Pastor (2019, pp. 291-313).

45 Por ejemplo, STJUE de 13 de marzo de 2014, asunto C-38/13.

46 El problema es que, según la doctrina del TJUE, la especial naturaleza de las tareas a realizar por los contratos de duración determinada o la persecución de un objetivo legítimo de política social sí se consideran razones justificativas que permiten establecer un trato diferente entre contratos de duración determinada e indeterminada, pero no lo es la mera existencia de una norma general y abstracta, como una Ley, que contenga esa diferencia de trato, o la mera naturaleza temporal de la relación de servicio, vid. Marín Alonso (2017).

47 Empezando por su misma y singular conceptualización, como apunta Fuentetaja Pastor (2020b, p. 32).

48 SSTJUE de 13 de septiembre de 2007, asunto C-307/05 y de 22 de diciembre de 2010, asuntos acumulados C-444/09 y C-456/09

49 Como bien señala el profesor Fuentetaja Pastor (2020b, p. 34), la cuestión es compleja -y a mi juicio paradójica-: el Derecho europeo prohíbe la discriminación en las condiciones de trabajo entre trabajadores temporales (en este caso, los funcionarios interinos) y trabajadores fijos (en este caso, los funcionarios de carrera) que se basen exclusivamente en la «temporalidad» de la relación. Lo determinante, con independencia de la misma, son las funciones desarrolladas. Pero el problema es que, en nuestro ordenamiento, casi la única nota diferenciadora de ambos tipos es, precisamente, la temporalidad del vínculo.

50 En cualquier caso, la exigencia de «urgencia» y «necesidad», a pesar de tratarse de conceptos jurídicos indeterminados, ya revelaba claramente una excepcionalidad caracterizada por la transitoriedad y ocasionalidad de las circunstancias, vid. Fuentetaja Pastor (2020b). 
diente a funcionarios de carrera; su obligación es proveer ese puesto para su efectiva cobertura por ellos $^{51}$. No hay, pues, discrecionalidad sustantiva decisional, ni, ahora, expresamente, margen temporal de alargamiento de la cobertura transitoria de la vacante ${ }^{52}$;

b) La sustitución transitoria de los titulares, pero «durante el tiempo estrictamente necesario» (a fin de evitar, de nuevo, que posibles dilaciones desemboquen en un tratamiento irregular). La interinidad por sustitución -lógica y naturalmente también de naturaleza transitoria- conlleva la simple sustitución temporal del funcionario de carrera por el interino, a tiempo completo o parcial, pero sin pérdida por el primero de su derecho a la plaza;

c) La ejecución de programas de carácter temporal, que no podrán tener una duración superior a tres años, ampliable hasta doce meses más por las Leyes autonómicas correspondientes. Por programas temporales habrá que entender, de manera sustantiva y no formal, cualquier actividad o tarea asumida por una Administración o entidad pública con carácter no permanente o estructural, estrechándose el margen de interpretación de tales características a través de la fijación formal del plazo máximo de duración de los mismos; y.

d) El exceso o acumulación de tareas por plazo máximo de nueve meses, dentro de un período de dieciocho meses. Conviene precisar que este supuesto de la interinidad de refuerzo no admite ningún tipo de prórroga, pero el nombramiento sí puede reiterarse, siempre que siga siendo necesario, y no se sobrepase el plazo máximo global de dieciocho meses.

Se acotan y restringen, pues, los presupuestos habilitantes, intentando impedir la extensión fraudulenta de una relación inicial -y por naturaleza- temporal o provisional por parte de la Administración pública (aunque realmente sin añadir mecanismo alguno específico de coerción al cumplimiento de los plazos, sanción a su incumplimiento o desincentivación a su uso reiterado) ${ }^{53}$.

Es evidente que el establecimiento -y su cumplimiento- de límites temporales -objetivos y con base legal- de duración de los nombramientos, con independencia en parte de la subsistencia o no de la causa del nombramiento, puede evitar o minimizar la cronificación de estas situaciones, y su correspondiente abuso por parte de la Administración, aunque no se entiende que sí se limite la interinidad por vacante pero no la interinidad por sustitución.

Como se ha dicho en este sentido, lo importante desde el punto de vista de la estabilidad de la relación que no es un concepto antitético a la temporalidad- es la configuración objetiva de las causas de finalización de ésta, limitando o eliminando incluso la discrecionalidad o el margen de apreciación de la Administración en su concurrencia (sobre todo en el caso de las letras c y d) ${ }^{54}$. El RD-Ley que comentamos se orienta en este sentido claramente, a pesar de mantener aún ciertos conceptos jurídicos susceptibles de interpretación («imposibilidad de cobertura por funcionarios de carrera» o el «exceso o acumulación de tareas»), aunque la clave quizás esté, desde una adecuada combinación entre mérito y versatilidad, en una progresiva y necesaria transición, obviamente no a la precarización funcionarial -en atención a las necesidades sociales objeto de prestación y servicio-, sino a la flexibilización y modulación espacio-temporal de las relaciones públicas de empleo, desde la satisfacción determinada, técnica e inmediata de necesidades, pero sin la necesaria -y rígida- conversión en empleo estructural siempre ${ }^{55}$.

51 Por ello, «la condición de la "imposibilidad" de cobertura por funcionarios de carrera debe ponerse en relación directa con el presupuesto habilitante de todo nombramiento de personal interino, esto es, la necesidad y urgencia justificadas, pues, conforme a una correcta interpretación de la norma, si tal urgencia no existe, porque no la impone la correcta prestación de los servicios, procede esperar a la tramitación de los procedimientos ordinarios de provisión o utilizar los procedimientos alternativos, de carácter voluntario o forzoso, en vez de proceder al nombramiento de un funcionario interino», Sánchez Morón (2020, p. 33).

52 Como se ha dicho, realmente la modalidad de interinidad por vacante, por uso y abuso, ha destacado sobremanera como instrumento básico y alternativo a una gestión adecuada de la cobertura de plantillas, y con la nueva limitación temporal de facto se convierte la interinidad en una relación a término -o al menos, mixta-, Morón Prieto (2021).

53 Aún más, en algún caso: no parece muy comprensible, por ejemplo, desde la perspectiva de la reducción de la temporalidad, la ampliación en tres meses de la duración máxima de los nombramientos del personal funcionario por exceso o acumulación de tareas.

54 Fuentetaja Pastor (2020a, p. 89).

55 Castillo Blanco (2020). Habría que pensar, así, dice el autor, en «puestos de trabajo más multifuncionales y polivalentes sin adscripción definitiva a unidades orgánicas permanentes, puestos temporales atendiendo a programas o proyectos, una reordenación del tiempo de trabajo con potenciación del trabajo a distancia, a tiempo parcial, flexible o en jornada partida; el establecimiento de jornadas complementarias en momentos punta de trabajo compensadas con días de descanso en períodos de menor intensidad laboral, y otras medidas de flexibilización de la movilidad y la distribución de efectivos se presentan como ineludibles en orden a evitar compartimentos estancos». 
Si las causas de nombramiento y sus límites materiales y temporales no se cumplían antes, ¿cómo asegurar que se van a cumplir ahora, aunque sean condiciones más objetivas y expresas? ${ }^{56}$ Se impone, por ello, una «necesaria disciplina en la autoorganización de sus recursos humanos por parte de las Administraciones públicas ${ }^{57}$, como reforma de fondo adicional a estas previsiones de simple «insistencia» -no sancionada en su elusión- en la condición temporal de la relación de interinidad.

\subsubsection{Principios y objetivos de los sistemas de selección}

La premisa -de diferenciación- es que los procedimientos de acceso a la condición de personal funcionario interino no son equiparables -completamente- a los de personal funcionario de carrera. También desde esta perspectiva se refuerza la -ambivalente- nota de temporalidad del vínculo jurídico al descartarse expresamente cualquier expectativa de permanencia ${ }^{58}$.

Sigue exigiéndose obviamente, en tanto empleados públicos, que los procedimientos de selección del personal interino sean públicos y respeten los -ineludibles- principios de igualdad, mérito y capacidad, aunque se sustituye ahora la «agilidad» por la «celeridad» de los mismos, y se añade que su finalidad debe ser -no sólo desde el punto de vista de la eficacia de cualquier actuación administrativa, sino en virtud de los requisitos de urgencia, necesidad y excepcionalidad del nombramiento- «la cobertura inmediata del puesto» (lo cual no supone sin embargo acabar con las también reconocidas bolsas de trabajo).

Aun siendo principios necesitados de interpretación -y de plasmación concreta en las normas correspondientes de desarrollo de cada Administración pública- lo cierto es que la «celeridad» parece exigir no sólo agilidad o flexibilidad, sustantiva y procesal, de los procesos de nombramiento, sino una cierta «rapidez» temporal de los mismos (dada la propia urgencia funcional en la cobertura del puesto).

En cualquier caso, se insiste ahora, «el nombramiento derivado de estos procedimientos de selección en ningún caso dará lugar al reconocimiento de la condición de funcionario de carrera» (art. 10.2 TREBEP).

En todo caso, conviene recordar que la decisión de nombrar personal interino no es un acto puramente discrecional, sino que debe responder a la cobertura de necesidades de nuevos efectivos en la Administración de que se trate, pero sin poder realizarse por funcionarios de carrera mediante los procedimientos de provisión ordinarios.

Como se preveía antes, la nueva redacción del art. 10.4 TREBEP presta una especial atención a la cobertura de las plazas vacantes ocupadas por interinos. No obstante, frente al mandato anterior, muchas veces incumplido (por falta de medidas de coacción y exigencia de responsabilidad ${ }^{59}$ ), de la inclusión de las vacantes en el mismo ejercicio del nombramiento del personal interino, o, a lo sumo, en el siguiente (y a salvo de la decisión de la definitiva amortización la misma), se remarca ahora la temporalidad expresa de esta causa habilitante ${ }^{60}$. Se impone -aunque teóricamente ya era obligatorio- a las Administraciones públicas la cobertura (ordinaria, habrá que entender) de todas las plazas vacantes ocupadas por interinos, mediante

56 Además, estaría el problema de la factibilidad de su asunción, de forma generalizada en el seno de todas las Administraciones públicas de nuestro país. Como bien se ha dicho, «fijar la interinidad funcionarial en plaza vacante en un plazo máximo de tres años no parece ocasionar nerviosismo en el debate pues no afecta a los actuales interinos, un ejercicio -una vez más- de mirada de corto alcance por parte de los detractores, más preocupados por el pasado que por el futuro, cuando a muchos gestores no se les escapa la -casi- imposibilidad de que en los próximos ejercicios presupuestarios la selección se ejecute en un plazo de tres años desde la fecha de ingreso del empleado interino», Boltaina Bosch (2021).

57 Carbonero Redondo (2020).

58 Hay que tener en cuenta, no obstante, que el art. 10.6 sigue estableciendo que al personal funcionario interino le será aplicable el régimen general del personal funcionario de carrera en cuanto sea adecuado a la naturaleza de su condición temporal. Por ello, han de aplicarse a la selección de funcionarios interinos los principios y normas establecidos en el Capítulo I del Título IV TREBEP, salvo que se refieran expresamente sólo a los funcionarios de carrera o al personal laboral, o bien sean incompatibles con la condición de interinidad o el carácter extraordinario y urgente del nombramiento.

59 Realmente, la redacción anterior del precepto sí imponía el deber de incluir en la Oferta toda plaza cubierta por personal interino, pero no que la existencia de plazas cubiertas por interinos conllevara o impusiera la consiguiente OPE con periodicidad anual, cuyo desarrollo parecía caer más dentro de la -amplia- potestad de autoorganización de las Administraciones Públicas. Ahora, la obligatoriedad de inclusión de todas las vacantes ocupadas por interinos en la oferta de empleo público del ejercicio de nombramiento o, a lo sumo, en el siguiente, aunque según lo previsto al respecto en la «normativa presupuestaria», se reitera en la D. A. 3. ${ }^{a}$ del RD-Ley 14/2021, de 6 de julio.

60 Es evidente que la regulación anterior no satisfacía los estándares exigidos en este punto por la jurisprudencia comunitaria. Baste recordar, así, que según la STJUE de 19 de marzo de 2020 (asuntos C-103/18 y 429/18), una normativa nacional que prevé la organización de procesos selectivos para cubrir de manera definitiva las plazas ocupadas provisionalmente por empleados públicos con una relación de servicio de duración determinada, así como los plazos concretos a tal efecto, pero que no garantiza que esos procesos se organicen efectivamente, no resulta adecuada para sancionar debidamente la utilización abusiva de tales relaciones de servicio ni 
cualquiera de los mecanismos de provisión o movilidad previstos. Esta ocupación es, por naturaleza, necesariamente transitoria y excepcional. Lo normal es pues, sin plazo específico, su ocupación por personal funcionario de carrera. Ahora bien, y para intentar evitar, a pesar de ello, la perpetuación -abusiva- de esta ocupación temporal, una vez transcurridos tres años desde el nombramiento se producirá inmediatamente el fin de la relación de interinidad ${ }^{61}$, pero además, se añade que la vacante sólo podrá ser ocupada por personal funcionario de carrera (no por otro interino, pues), salvo que lógicamente el correspondiente proceso selectivo quede desierto, en cuyo caso sí se podrá efectuar otro nombramiento de personal funcionario interino. Dejando de lado la válvula de escape final, de cuyo desarrollo y resultado podrá derivarse o no la continuación de situaciones encadenadas de interinidad, lo cierto es que el precepto enlaza a la finalización del plazo máximo de interinidad por vacante (tres años) una consecuencia quizás excesiva: a mi juicio, lo que se prohíbe es la ocupación fáctica estructural de una plaza, con abuso de la relación de temporalidad, pero no que, si se dan las circunstancias legales, una vez acabada la relación, se pueda nombrar a otro interino o interina (con plazo máximo de ocupación respectivo). La solución es, en este punto, estricta: una vez «agotada» la relación de interinidad -por el transcurso de tres años-, la plaza, con independencia de las circunstancias concurrentes, de la existencia o no de presupuestos habilitantes (es decir, que la plaza siga vacante) y de que pueda existir la posibilidad de nuevos nombramientos temporales, sólo y exclusivamente podrá ocuparse por funcionarios de carrera (tras el correspondiente sistema selectivo, pues). Como dice el propio preámbulo de la norma, «se endurecen -claramente- las previsiones legales en cuanto a la duración máxima del nombramiento del personal interino por vacante, como medida preventiva para evitar un uso abusivo de esta figura para ejercer funciones de carácter permanente o estructural». Como solución transitoria ( $\mathrm{y}$ teniendo en cuenta la duración de los procesos de selección) se establece finalmente también que, excepcionalmente, el personal funcionario interino sí podrá permanecer en la plaza ocupada temporalmente cuando se hubiera publicado ya la correspondiente convocatoria dentro del plazo -máximo- de los tres años, a contar desde la fecha del nombramiento del funcionario interino, pudiendo permanecer en la misma hasta la resolución de la convocatoria, y sin que su cese pueda dar lugar a compensación económica (nuevo art. 10.4 TREBEP in fine).

\subsubsection{Objetivación de las causas de terminación de la relación interina}

Sí resulta acertada y positiva (al menos desde una perspectiva no tanto clarificadora, en tanto que el precepto resulta en cierta forma redundante, como explicitadora de la regulación del cese), frente a la mínima previsión anterior sobre el cese de los funcionarios interinos por las mismas causas previstas para la pérdida de la condición de funcionario de carrera (causas comunes), junto con la propia y lógica desaparición o término de la causa de nombramiento, la inclusión ahora de causas específicas de cese -0 , al menos, de su enunciación expresa-, y, como tal, «sin derecho a compensación alguna» (STJUE de 22 de enero de 2020).

El cese, además, no es discrecional u optativo (dado que, de hecho, las propias causas de cese ya se entendían como claramente objetivas, por su inmediata vinculación a los hechos objetivos determinantes de la extinción de la relación ${ }^{62}$ ), sino estrictamente causal: la Administración empleadora debe formalizar de

para eliminar las consecuencias de la infracción del Derecho de la Unión, pues su aplicación no tendría ningún efecto negativo para el empleador.

61 Se alinea así el precepto con la propia regulación temporal del régimen de ejecución de las Ofertas de Empleo Público (art. 70.1 TREBEP), como plazo de ejecución «improrrogable» pero con ausencia -y de ahí su falta de operatividad- de consecuencias aparejadas a su incumplimiento (más allá de la posibilidad de indemnización judicial). Este plazo, además, ha sido declarado como «esencial» por la jurisprudencia (así, STS 4178/2018, de 10 de diciembre), determinando su inobservancia la propia caducidad de la convocatoria correspondiente, por incurrir en un vicio de anulabilidad, e incluso antes ya se habían anulado ofertas de empleo público por no respetarlo. Igualmente, el TJUE ha venido utilizando este mismo margen temporal para la calificación de las situaciones temporales como «injustificadamente largas». Como dice por ejemplo la reciente Sentencia de 28 de junio de 2021 , «salvo muy contadas y limitadas excepciones, los procesos selectivos no deberán durar más de tres años a contar desde la suscripción del contrato de interinidad, de suerte que si así sucediera estaríamos en presencia de una duración injustificadamente larga. Dicho período prolongado de forma anómala, en el marco de varios nombramientos o de uno solo, ocupando el mismo puesto de trabajo de modo ininterrumpido y desempeñando de forma constante y continuada las mismas funciones, cuando el mantenimiento de modo permanente de dicho empleado público en esa plaza vacante se deba al incumplimiento por parte del empleado de su obligación legal de organizar un proceso selectivo al objeto de proveer definitivamente la mencionada plaza vacante, ha de ser considerada como fraudulenta».

62 Esta vinculación se pone de manifiesto incluso en los supuestos de constatación judicial de una situación de abuso, puesto que en estos casos el personal interino sí tiene derecho a mantenerse en su cargo o en el ejercicio de las funciones encomendadas, mientras no se produzca, como criterio o resolución determinante (desde el punto de vista sustantivo), la causa legal específica que legitima -e impone- su cese, tal y como ha declarado la jurisprudencia del TS. 
oficio -aunque sin plazo- la finalización de la relación de interinidad «fáctica» o "abusiva», es decir, fuera de la cobertura de la causa que la justificaba, o, simplemente, por concurrencia de alguna de las causas establecidas en el nuevo art. 10.3 TREBEP: a) Por la cobertura reglada del puesto por personal funcionario de carrera a través de cualquiera de los procedimientos legalmente establecidos (causa general que, lógicamente, tiene su aplicación en los casos de cobertura por vacante, más que reglada, ordinaria o común); b) Por razones organizativas que den lugar a la supresión o a la amortización de los puestos asignados; c) Por la finalización del plazo autorizado expresamente recogido en su nombramiento; y d) Por la finalización de la causa que dio lugar a su nombramiento.

Estas causas específicas de cese concretan o exteriorizan en definitiva la «urgencia y necesidad» general que ampara genéricamente la existencia de los propios funcionarios interinos ${ }^{63}$. Aluden, de nuevo, al carácter necesario e imperativamente temporal de esta relación de servicios, que ha de finalizar por el transcurso del plazo máximo establecido o por la finalización de la causa determinante del nombramiento. No obstante, su nueva positivización no parece tener el mismo alcance y virtualidad en todos los casos. Porque el cese automático por cobertura reglada u ordinaria del puesto ocupado transitoriamente no es sino traslación del cumplimiento de la primera condición resolutoria del art. 10.1.a) TREBEP. Pero sin embargo, que por razones -genéricamente- organizativas (¿sin ningún tipo de justificación o motivación?) se pueda acordar la supresión o amortización de los puestos ocupados por interinos, pese a ser una indudable manifestación de la naturaleza objetiva y funcional de éstos -y de la potestad administrativa de autoorganización-, vinculada al puesto, sí puede plantear determinados interrogantes -y vías de escape- para el caso de interinos de larga duración con finalización de su relación sin condición resolutoria equivalente y sin indemnización alguna ${ }^{64}$.

\subsubsection{Los funcionarios interinos siguen sin tener un «estatuto» propio}

La opción del RD-Ley 14/2021, de 6 de julio, de mantener una mera «regulación analógica» del régimen jurídico del personal interino (art. 10.6 TREBEP) conduce a la imprevisión de cualesquiera normas sobre el conjunto de derechos y obligaciones integrantes de su relación estatutaria ${ }^{65}$. Quizás también, desde esta perspectiva, se pueda seguir confundiendo entre la temporalidad del nombramiento y la estabilidad funcional en el desempeño -durante el tiempo del mismo- de las funciones propias del puesto de trabajo ocupado ${ }^{66}$.

Porque es evidente que, durante el mismo, todo funcionario interino tiene los derechos y obligaciones establecidos en la normativa correspondiente (el TREBEP, de hecho, ya atribuye expresamente muchos de los derechos que reconoce al conjunto de los empleados públicos). En principio, y por la propia convergencia de regímenes, los mismos que los funcionarios de carrera, salvo: i) los que sean inherentes a su condición como tal (singularmente, el derecho al cargo) y ii) más ambiguamente, los que sean «inadecuados» a la naturaleza de su condición temporal y al carácter extraordinario y urgente de su nombramiento.

Las excepciones, por su misma naturaleza jurídica, no permiten conformar un régimen general (en positivo). Sí es verdad que puede ser más fácil identificar aquellos derechos inherentes a la condición de fijeza temporal de los funcionarios de carrera (a pesar de su remisión indefinida a la «condición» como tales), pero resulta llamativo que, frente a dicho proceso de acercamiento de regímenes y cuando la jurisprudencia comunitaria insiste en que el carácter temporal no es condición suficiente de diferenciación de tratamiento ${ }^{67}$, se fije ahora, a través de operaciones de deducción siempre complicadas ${ }^{68}$, el estatuto jurídico del personal interino en función de que los derechos comunes o generales no sean adecuados a la naturaleza de su

63 Por ello, debe entenderse que el personal interino también puede ser cesado por circunstancias sobrevenidas que hagan desaparecer el presupuesto de hecho habilitante del nombramiento, que en todo caso es una situación de necesidad y urgencia en la cobertura del servicio o la prestación de las funciones que se le asignen, Sánchez Morón (2020, pp. 100 y 158).

64 En este último sentido, y desde el afán de fortalecimiento -legal- de la temporalidad -y correlativa proscripción, fáctica, de su abuso-, la norma puede haber confundido interinidad con precariedad de derechos, con seguridad jurídico o incluso con estabilidad -dentro de la relación y el plazo de interinidad-, vid., sobre el tema, Fuentetaja Pastor (2020a, p. 93).

65 Vid., por ejemplo, Martín de Arrate (2021).

66 Vid. al respecto por ejemplo Brufao Curiel (2021), especialmente pp. 39 y ss.

67 Como ha recordado el TJUE, las razones objetivas que avalarían una diferencia de trato han de venir justificadas por la existencia de «elementos precisos y concretos», a fin de «verificar si dicha desigualdad responde a una necesidad auténtica, si permite alcanzar el objetivo perseguido y si resulta indispensable al efecto», Sentencia de 5 de junio de 2018, asunto C-677/16.

68 Como dice el profesor Sánchez Morón (2020, p. 68), «se han despejado algunas incógnitas y se han reconocido a los funcionarios interinos algunos derechos de los que no disfrutaban, a diferencia de los de carrera. Pero aún quedan bastantes dudas respecto de otros, ya que no es fácil deducir en todos los casos si las razones que, en principio, se aducen como justificación de la desigualdad son objetivas y suficientes». 
condición temporal (y al carácter extraordinario y urgente del nombramiento, que constituye obviamente la causa habilitante del mismo, inicial y reglada, pero que no tiene porqué incidir luego, materialmente, en el régimen de derechos y obligaciones propios del puesto ocupado y de las funciones desempeñadas).

En cualquier caso, la opción del legislador (de urgencia) ha sido la de no incluir o desarrollar tal régimen jurídico, desaprovechando quizás la oportunidad no sólo de singularizarlo -y justificar, así, el trato diferente más allá de su condición temporal ${ }^{69}$ - sino incluso de incidir en las propias especialidades del mismo puestas de manifiesto ya por la jurisprudencia ${ }^{70}$.

\subsection{Responsabilidad de la Administración en los casos de abuso de la relación de temporalidad}

\subsubsection{Invalidez absoluta de las actuaciones de abuso}

No parece suficiente, para cumplir con las reseñadas exigencias comunitarias, la introducción de ciertas modificaciones positivas en el régimen del personal interino, puesto que el problema no es tanto de la «regulación» como de la "gestión» (inadecuada o directamente fraudulenta) de la misma. A partir de su entrada en vigor puede haber más prevención, pero, ¿y la sanción -efectiva y disuasoria, además- de los comportamientos contrarios al principio de igualdad de los trabajadores?

Se añade así en este sentido una nueva D. A. 17. ${ }^{a}$ al TREBEP, relativa específicamente a las medidas relativas al control de la temporalidad en el empleo público.

Obviamente, y de principio, no se trata de un régimen sancionador, aparejado -formalmente- y consecuente -materialmente- a la vulneración de los deberes, sustantivos y temporales, contenidos en el art. 10. Se habla así, de hecho, de régimen de responsabilidad, constituido por «medidas» o «mecanismos», no de sanciones. La terminología, en cualquier caso, sería indiferente, siempre y cuando se tratara de "previsiones» proporcionales, eficaces y disuasorias para garantizar el cumplimiento del deber de evitar abusos en la temporalidad del personal al servicio de las Administraciones Públicas.

$Y$ no parece realmente que la primera medida responda a estos requisitos exigidos por la jurisprudencia comunitaria.

Señala así el apartado tercero de esta nueva D. A. 17. ${ }^{\text {a }}$ TREBEP que «todo acto, pacto, acuerdo o disposición reglamentaria, así como las medidas que se adopten en su cumplimiento o desarrollo, cuyo contenido directa o indirectamente suponga el incumplimiento por parte de la Administración de los plazos máximos de permanencia como personal temporal será nulo de pleno derecho».

La disposición puede parecer contundente, pero realmente sólo está diciendo que la vulneración de una norma legal conlleva la invalidez absoluta de la actuación o norma que la provoque. No parece por ello que se trate, sin más, de una medida claramente eficaz o disuasoria de futuros incumplimientos (sí puede entenderse como proporcional a la carga de antijuridicidad de la acción). Es la consecuencia normal de cualquier incumplimiento normativo grave por parte de la Administración. El problema es, además, que no sólo en teoría, sino desde una perspectiva aplicada, su funcionalidad también parece discutible. Cabe asumir sin problemas la nulidad radical de cualquier acto, acuerdo o pacto -siempre que en estos dos últimos casos se traduzcan en un acto administrativo concreto- o disposición reglamentaria que establezca una norma con rango de Ley, como es el RD-Ley que comentamos, pero no puede decirse lo mismo de las «medidas» de cumplimiento o desarrollo, entendidas en sentido genérico, salvo que se entienda que las mismas también conllevan la emisión de los actos administrativos correspondientes. Pero, el mantenimiento de un interino en sustitución de un funcionario de carrera más allá del tiempo estrictamente necesario, ¿en qué tipo de acto positivo de los enunciados encajaría a los efectos de sancionar no a la Administración incumplidora, sino su actuación formalizada? Como sabemos, el abuso en la temporalidad se ha producido, en la mayoría de los casos, no a través de actos o acuerdos expresos (parece evidente) sino de actuaciones elusivas, dilatorias o simplemente de inacción, cuando no amparadas en una determinada interpretación de los conceptos jurídicos indeterminados que, como hemos visto, se han mantenido dentro de los supuestos habilitadores del

69 Como ya se ha reseñado, el Acuerdo Marco de la Directiva no prohíbe la desigualdad de trato entre empleados según el tipo de vínculo jurídico que les une al empleador, sino sólo la discriminación por razón de la duración de la misma.

70 Cabe recordar así por ejemplo la doctrina relativa a las «relaciones inusualmente largas», donde, según el TS, no hay, a diferencia del personal laboral, alteración de la naturaleza jurídica temporal de la relación con la Administración, pero quizás sí una auténtica asimilación material al régimen de los funcionarios de carrera (al establecerse la subsistencia y continuación de la relación de empleo), en relación fundamentalmente con los derechos (profesionales y económicos) ostentados, vid. en este sentido, Gordo González (2021). 
nombramiento de personal interino ${ }^{71}$. El control del respeto de la naturaleza temporal del personal interino habría que referirlo más bien a la actuación y gestión ordinaria de las Administraciones públicas, más que a sus actos formalizados. Además, aún con el afán de reforzar dicho control, lo cierto es que el precepto presenta una extensión objetiva discutible al incluir no sólo actuaciones cuyo contenido vulnere la norma de forma directa, sino también indirectamente, lo cual parece chocar con unas premisas de seguridad jurídica en cuanto a la aplicación del precepto, con el propio discernimiento de su alcance y, formalmente, con la necesidad de una «tipificación» estricta de las causas -excepcionales- de nulidad absoluta o de pleno derecho. Pero es que además, y finalmente, la «intensidad» de la reacción -no prevención-se diluye en el contraste con el único deber cuya infracción se castiga: porque el precepto sanciona no todo incumplimiento de los requisitos establecidos para poder nombrar y mantener a personal funcionario, sino sólo y exclusivamente la violación de los plazos máximos de permanencia. Es importante, y el objeto central de la norma, pero es evidente que hay otros requisitos, empezando por la necesaria y suficiente justificación de la urgencia y necesidad cuya inobservancia, vulneración o contradicción también conllevan una relación fraudulenta de la temporalidad. En estos casos, el acto no es nulo de pleno derecho, pero ¿puede ser anulable al menos? Parece deducirse que el abuso sólo existe en los casos de cronificación, más allá del plazo legal, de la situación de temporalidad, pero no en los supuestos de incumplimiento de alguno de los otros requisitos (por ejemplo, que el programa que motiva el nombramiento no sea realmente temporal).

Pero más allá de estas dudas interpretativas, lo cierto es que la medida no parece suficientemente efectiva y disuasoria de futuros comportamientos de abuso, que no van a acarrear una «sanción» -aún en sentido amplio- para la Administración incumplidora, sino, como mucho, y en vía judicial seguramente, la expulsión del acto o norma viciados del ordenamiento jurídico.

\subsubsection{Compensaciones económicas}

La segunda medida prevista en esta D. A. tiene ya un contenido más específico, concreto y resarcitorio, y en principio más ajustada a las exigencias comunitarias ${ }^{72}$, puesto que se establece que estos incumplimientos del plazo máximo de permanencia darán lugar, directamente, a una compensación económica para el personal funcionario interino afectado, que será equivalente a veinte días de sus retribuciones fijas por año de servicio, prorrateándose por meses los períodos de tiempo inferiores a un año, hasta un máximo de doce mensualidades. El derecho a la compensación nacerá a partir de la fecha del cese efectivo y la cuantía estará referida exclusivamente al nombramiento del que traiga causa el incumplimiento (es decir, al título jurídico de cobertura). En cualquier caso, y es evidente, no habrá derecho a compensación en caso de que la finalización de la relación de servicio sea por causas disciplinarias ni por renuncia voluntaria.

Se trata, en fin, de una medida compensatoria - pero no estrictamente resarcitoria, como una auténtica indemnización por responsabilidad patrimonial ${ }^{73}$ - novedosa en el caso del personal funcionario interino ${ }^{74}$,

71 Un ejemplo de ello puede verse en la D. A. 3. a del propio RD-Ley 14/2021, de 6 de julio, donde se permite, como excepción al espíritu restrictivo de la norma, sin ningún criterio orientativo al respecto para su ejercicio, el nombramiento de personal interino en las plazas vacantes por jubilación que se produzcan en cada ejercicio presupuestario, con la finalidad -evidentemente genérica e interpretable- de «mantener una adecuada prestación de los servicios públicos». Fuera del art. 10.1.a) TREBEP, ¿no es necesario aquí acreditar la urgencia y necesidad ni la imposibilidad de cobertura por funcionarios de carrera? y, ¿no hay límite máximo temporal de los nombramientos en estos casos?

72 Vid. Mateos Martínez (2020, pp. 413-415): «Con su último pronunciamiento de 19 de marzo de 2020, el TJUE abre la puerta a que los tribunales españoles impongan a la Administración el pago de indemnizaciones ejemplarizantes a los funcionarios interinos que están sufriendo eternos encadenamientos de nombramientos y atados a una precariedad contraria tanto al Derecho de la Unión Europea como a nuestro propio Derecho interno».

73 No obstante, desde el ámbito doctrinal sí se ha entendido que se trataría de una auténtica indemnización consecuencia del abuso padecido, como una «sanción» que se le impondría a la Administración al haber incurrido o provocado el mismo, Fuentetaja Pastor (2020c, p. 224). A mi juicio, sin embargo, una auténtica sanción administrativa (¿disciplinaria?) debería ser fruto consecuente de la infracción de una previa obligación específica al respecto, aplicación de una sanción tipificada como tal y a través del procedimiento correspondiente, lo que no sucede en estos casos. De hecho, difícilmente podría sostenerse que nuestro ordenamiento jurídico ampara -o amparaba - esta solución, el surgimiento directo de un derecho a ser indemnizado por haber sido objeto de abuso, más allá de su derivación -indirecta- del Derecho comunitario que hemos comentado, y de que ahora, sin modificación sistemática de la parte sustantiva correspondiente, se haya introducido al respecto la nueva D. A. 17. ${ }^{\text {a }}$ TREBEP.

74 No sucede lo mismo en el caso del personal laboral temporal, también incluido dentro de esta D. A. 17. a TREBEP. E incluso, se ha dicho, involutiva, con respecto al mismo: «De su tenor literal parece deducirse que estamos ante una nueva forma de extinción exprés de un contrato laboral devenido indefinido como consecuencia del incumplimiento de los límites máximos de los plazos de contratación temporal que tiene entre otras consecuencias una menor indemnización por extinción y, desde luego, la imposibilidad de reconocimiento de la condición de indefinido no fijo con las consecuencias ya conocidas», Morón Prieto (2021). 
más allá del debate sobre la suficiencia cuantitativa de la misma. En este sentido se ha señalado que, aunque puede ser positivo la fijación de una indemnización unificada en el caso de la superación de los plazos máximos de permanencia, podrían destacarse tres objeciones: i) No se reconoce el derecho a indemnización en todos los supuestos de extinción de los nombramientos de los funcionarios interinos; ii) Se excluye, aparentemente, el tiempo de servicio en régimen de interinidad desempeñado antes del contrato o nombramiento del que trae causa el incumplimiento; y iii) Se limita enormemente su virtualidad y extensión aplicativa, al aplicarse sólo a los nombramientos posteriores a la entrada en vigor de la norma ${ }^{75}$.

\subsubsection{Otras proyecciones del principio de responsabilidad}

Al margen de las dos previsiones anteriores, la nueva D. A. 17. ${ }^{\text {a }}$ TREBEP incluye también otras tres exigencias vinculadas, mucho más tenuemente, al principio de responsabilidad por el abuso de las relaciones de mera temporalidad.

En primer lugar se señala así que las Administraciones Públicas serán responsables del cumplimiento de las previsiones contenidas en la presente norma, mención totalmente vacía de contenido, evidente pero imprecisa sobre el verdadero alcance de tal responsabilidad. Y, en especial, «velando» (lo cual tampoco implica una imperativa función de control con responsabilidades jurídicas concretas aparejadas) por evitar cualquier tipo de irregularidad en la contratación laboral temporal y los nombramientos de personal funcionario interino. Es evidente que no todo tipo de irregularidad conlleva la invalidez de la actuación (en el nombramiento o en el desarrollo de la relación de interinidad), pero en cualquier caso se trata de una previsión sistemáticamente descontextualizada e inoperativa en el fondo, sin incorporar auténticos mecanismos de prevención o sanción frente a las ilegalidades en materia de abuso del personal interino ${ }^{76}$.

En la misma línea -de debilidad e inconsistencia jurídicas- se señala a continuación que las Administraciones públicas han de promover (sic), en sus ámbitos respectivos ( $i$ ?), el «desarrollo de criterios de actuación que permitan asegurar el cumplimiento de esta disposición (¿sólo de sus mínimas y ambiguas exigencias o de toda la norma donde se incluye?), así como una actuación coordinada de los distintos órganos con competencia en materia de personal». De nuevo, una formulación enormemente vaga, imprecisa y carente de operatividad, situada más en el ámbito de la voluntariedad que en el de la responsabilidad (jurídica), más allá de las comprensibles dificultades competenciales de establecer una normativa básica sobre la -amplísima- potestad de autoorganización administrativa en nuestro país.

Y con más vaguedad aún, finalmente se señala que «las actuaciones irregulares en la presente materia darán lugar a la exigencia de las responsabilidades que procedan de conformidad con la normativa vigente en cada una de las Administraciones Públicas».

Al margen de los problemas de técnica legislativa -y comprensión normativa-, lo cierto es que parece evidente que no estamos antes auténticos mecanismos sustantivos y-directamente- operativos de exigencia de responsabilidad jurídico-pública, ni mucho menos ante medidas (eficaces) de control de la temporalidad inválida (no sólo irregular) o instrumentos de desincentivación (efectiva) de los futuros abusos en este ámbito, aún dentro de la limitada capacidad de regulación básica.

\subsection{Previsiones inmediatas o «pro legislatura»: ampliación de los procesos de estabilización del empleo temporal}

\subsubsection{Nuevo -y agilizado- proceso de estabilización: el objetivo del $8 \%$}

La segunda parte del Real Decreto-Ley se dedica ya a intentar solucionar el grave problema existente, es decir, intentar reducir la altísima tasa de temporalidad en el empleo público con eliminación de las situaciones de abuso, fraude o discriminación entre trabajadores, y con un objetivo específico: situar la tasa de cobertura temporal por debajo del $8 \%$ de las plazas estructurales.

75 Gordo González (2021).

76 Tal y como se ha dicho en este sentido, «la ley debería establecer con precisión que, con independencia de la responsabilidad penal y disciplinaria que les pudiera corresponder, las autoridades y funcionarios a quienes se impute, por dolo o negligencia, la prolongación irregular de un nombramiento de interinidad, deberían responder personalmente de las indemnizaciones que la Administración o entidad competente tenga que abonar a las personas que han sido objeto de abuso en la situación de interinidad, en los términos en que así se declare por sentencia judicial», Sánchez Morón (2020, p. 159). 
En este sentido, su art. 2 establece la ampliación de los procesos de estabilización de empleo temporal ya vigentes, autorizándose directamente un tercer proceso ${ }^{77}$.

Se autoriza, así, una tasa adicional para la estabilización de empleo temporal que incluirá las plazas de naturaleza estructural -que no se definen- que, estén o no dentro de las relaciones de puestos de trabajo, plantillas u otra forma de organización de recursos humanos que estén contempladas en las distintas Administraciones Públicas y estando dotadas presupuestariamente, «hayan estado ocupadas de forma temporal e ininterrumpidamente al menos en los tres años anteriores a 31 de diciembre de 2020 ».

Las ofertas de empleo que vehiculicen estos procesos de estabilización han de aprobarse y publicarse en los respectivos diarios oficiales antes del 31 de diciembre de 2021, y serán coordinados por las Administraciones públicas competentes (que lo son, de hecho, para su entera gestión y desarrollo en principio). La publicación de las convocatorias deberá producirse, a su vez, antes del 31 de diciembre de 2022 y la resolución final de los procesos selectivos, antes del 31 de diciembre de 2024.

Ahora bien, desde el derecho europeo estos procesos de consolidación se reputarían seguramente inadecuados, en cuanto que consecuencia jurídica sancionadora al abuso puesto que, si bien aquellos ponen fin al abuso desde una perspectiva objetiva, no resarcen el abuso padecido por el funcionario interino, desde una perspectiva subjetiva -la más difícil de encajar, por cierto, dentro de nuestro ordenamiento-, en la medida en que no garantiza la estabilidad de los afectados (hay que tener en cuenta que se consolidan plazas, no personas) ${ }^{78}$.

\subsubsection{Sistema de selección preferente: concurso-oposición}

Es evidente, y así se impone, que el desarrollo de estos procesos selectivos ha de garantizar en cualquier caso el cumplimiento de los principios de libre concurrencia, igualdad, mérito, capacidad y publicidad, aunque para su articulación específica se remite a la negociación en cada uno de los ámbitos territoriales de que se trate.

Ahora bien, este precepto da un paso más, señalando que, sin perjuicio de lo establecido en su caso en la normativa propia de función pública de cada Administración o la normativa específica (de nuevo, desde la máxima ambigüedad expositiva, porque, como mucho, a lo que habría que atender sería a la posible existencia de previsiones al respecto en la posible legislación autonómica correspondiente), «el sistema de selección será el de concurso-oposición, con una valoración en la fase de concurso de un $40 \%$ de la puntuación total», y en la que «se tendrá en cuenta mayoritariamente la experiencia en el cuerpo, escala, categoría o equivalente de que se trate» en el marco de la negociación colectiva correspondiente.

La previsión entronca claramente -y se justifica- con la posibilidad, reconocida jurisprudencialmente, de modular o flexibilizar la concurrencia en los procesos selectivos por parte del personal interino (SSTC $67 / 1989$, de 18 de abril y $86 / 2016$, de 28 de abril) ${ }^{79}$, beneficiando por ejemplo al personal temporal a través de la valoración como mérito -no como requisito- de los «servicios prestados» en la Administración, siempre y cuando dicha ponderación no sea determinante de la nota final (STC 107/2003, de 2 de junio).

Pero en cualquier caso se trata de una fórmula -excesivamente homogeneizadora, y, por ello, complicada de articular en todos los casos- claramente favorecedora de la posición del personal interino ${ }^{80}$, encauza-

77 La solución, bien que de urgencia, contingente y fruto evidentemente de un problema enquistado y general, no es, también parece claro, la fórmula ideal para la solución efectiva y adecuada -sostenible- de la cuestión, que debería pasar, más bien, por una reflexión general sobre los procedimientos y tiempos de los sistemas de selección siempre sobre la base de una planificación inteligente previa de los recursos humanos disponibles, las necesidades y vacantes y los medios económicos disponibles. Sobre estos procesos puede verse Roqueta Buj (2020, pp. 9-45).

78 Fuentetaja Pastor (2020c, p. 214). Como bien dice el autor, el juicio negativo que se vierte por la jurisprudencia comunitaria sobre los procesos de consolidación en cuanto al plano subjetivo, relativo al funcionario objeto de abuso, «resultan mucho más inquietantes», al dirigirse a la propia configuración sustantiva de aquellos procesos. Y «se trata de consideraciones difícilmente cohonestables con los principios de igualdad y de mérito y capacidad y que, en última instancia, penden sobre los fundamentos mismos de los procesos de consolidación, según se conceptualicen como medios de estabilización del personal temporal o de reducción estructural de la temporalidad». También, Canal Fernández (2019).

79 Según el TC, la valoración en el acceso a la función pública de los servicios prestados o de la experiencia en el servicio, aunque supone un trato de favor frente a quienes no pueden acreditarlos, no es contrario de por sí al art. 23.2 CE, ya que responde a los criterios de mérito que se contemplan en el art. 103,3 CE, siendo lícito incluso valorar preferentemente ese tipo de méritos, frente a otros, en la fase de concurso, ya que el objetivo de facilitar la consolidación del empleo temporal tampoco es ilegítimo. Ahora bien, dichos méritos no pueden ser ponderados de manera desproporcionada, irrazonable o arbitraria, de tal manera que se impida toda posibilidad de acceso a los aspirantes que no fueran interinos o personal temporal (STC 67/1989, de 18 de abril, en donde la valoración de los méritos por servicios prestados que se juzgaba podía llegar, incluso, hasta el $45 \%$ de la puntuación total del concurso-oposición).

80 Por ejemplo, Mauri i Majós (2018, p. 82 y ss.). 
da a su estabilización institucional a través de la participación en los correspondientes procesos selectivos, aunque no determinante -al recaer dentro del «límite de lo tolerable» (por ejemplo, STS de 31 de mayo de 2005 , rec. 6002/2001) - ${ }^{81}$, de la resolución definitiva de aquéllos (que es lo que vulneraría el marco constitucional de referencia y lo que expresamente prohíbe el art. 61.3 TREBEP).

Si así se hubiera previsto en la normativa específica sectorial o de cada Administración, los mecanismos de movilidad o de promoción interna previos de cobertura de plazas serán compatibles con los procesos de estabilización.

Finalmente, y como prevención (habilitadora de la propia posibilidad de la reforma), se prevé expresamente que de la resolución de estos procesos de consolidación no podrá derivarse, en ningún caso, incremento de gasto ni de efectivos, debiendo ofertarse en los mismos necesariamente plazas de naturaleza estructural que se encuentren desempeñadas por personal con vinculación temporal.

Al respecto, cabe señalar que en principio sí sería posible controlar el propio crecimiento cuantitativo del personal, puesto que simplemente se ofertarían plazas ya creadas, a fin de su cobertura indefinida, pero, lógicamente, el gasto no sólo dependerá de ello sino, en gran medida, del propio grado personal del personal que logre consolidar las plazas. El problema -y el margen de discrecionalidad- puede ser la determinación de las plazas de naturaleza estructural, y no coyuntural, que pueden ofertarse, así como la interpretación del inciso final, que curiosamente no hace referencia al personal funcionario interino sino, mucho más ampliamente, al personal con vinculación temporal.

\subsubsection{Compensaciones económicas}

Por lo demás, los funcionarios interinos -y el personal laboral temporal- que, estando en activo, se presenten a estos procesos de consolidación pero no los superen, con finalización por tanto de su relación temporal con la Administración, también tendrán derecho a una compensación económica equivalente a veinte días de retribuciones fijas por año de servicio, prorrateándose por meses los períodos de tiempo inferiores a un año, hasta un máximo de doce mensualidades.

\subsubsection{Régimen transitorio de los procesos selectivos ya convocados}

Los procesos selectivos para la cobertura de plazas incluidas en las ofertas de empleo público aprobadas en el marco de los procesos de estabilización de empleo temporal previstos en el art. 19.uno.6 de la Ley 3/2017, de 27 de junio, de Presupuestos Generales del Estado para el año 2017, y 19.uno.9 de la Ley 6/2018, de 3 de julio, de Presupuestos Generales del Estado para el año 2018, cuya convocatoria hubiere sido publicada en los respectivos diarios oficiales con anterioridad a la fecha de entrada en vigor del RD-Ley 14/2021, seguirán desarrollándose lógicamente de acuerdo a las previsiones de las respectivas convocatorias. No obstante, sí se establece obligatoriamente que dichos procesos deberán finalizar antes del 31 de diciembre de 2024.

\subsection{Medidas estratégicas (e inconcretas)}

Desde una más que dudosa ubicación sistemática (explicable solamente desde la vaguedad e insustancialidad de su contenido, pero en ningún caso por el carácter secundario de su potencialidad y efectos), la D. A. 4. ${ }^{a}$ enuncia, muy genéricamente, una serie de medidas estratégicas o programáticas para la agilización de los procesos selectivos. Ello contrasta, así, con la repercusión, sí sustantiva, de su falta de aplicación en muchos casos, con las consecuencias ya reseñadas de la prolongación indebida de la ocupación temporal de puestos reservados a funcionarios de carrera o el propio abuso -transitorio- de la relación de interinidad en la prestación de servicios propios de puestos estructurales.

El problema -o la causa del fraude- en estos casos es doble ( $\mathrm{y}$ al menos aquí no imputable a decisiones o dilaciones directamente políticas): primero, el incumplimiento genérico de la causa habilitante del nombramiento de personal interino (urgente y extraordinaria necesidad), junto con, en su caso, los plazos máximos de duración del vínculo; y segundo, y además, la falta de diligencia o impulso adecuado -por no exigir utilidad y celeridad- de los propios procesos selectivos de provisión de los puestos temporalmente ocupados.

81 Vid., por ejemplo, Cuenca Cervera (2018). 
Frente a ello -realidades- esta D. A. $4 .^{\text {a }}$ plantea medidas -ideales- que obviamente, desde su carácter dispositivo, o al menos no vinculante directamente, necesitan de la colaboración de cada Administración pública en su momento.

Éstas deben asegurar, como obligación de resultado, el cumplimiento del plazo establecido para la ejecución de los procesos de estabilización. Lo cual resulta sorprendente, porque estos plazos se recogen, ahora, en una norma legal: las Administraciones deben asegurar que van a cumplirse los mandatos legales. Obviamente, esto no es agilidad, sino cumplimiento legal (lo cual no añade nada desde el punto de vista de la celeridad o impulso óptimo de los trámites administrativos correspondientes). Y, además, es reflejo de la máxima desconfianza del propio legislador hacia su producto.

Este mandato de aseguramiento debe realizarse mediante la adopción de medidas apropiadas para un desarrollo ágil de los procesos selectivos. Hay que entender, entonces, que el propósito de esta D. A. 4. ${ }^{a}$ no es sólo asegurar el cumplimiento de los plazos legales, sino promover una cierta agilización o aceleración aún no concretada- del desarrollo de los procesos de selección para la cobertura de las plazas a estabilizar. Y para ello «propone», en abierto, como posibles medidas, y sin constituir lógicamente fórmulas uniformes y vinculantes, la posibilidad de reducción plazos, digitalizar procesos o acumular pruebas en un mismo ejercicio, «entre otras».

Se trata, en cualquier caso, de medidas lógicas de agilización de los procedimientos, también los selectivos, donde además los interesados son siempre empleados públicos temporales para los que ya resultaría obligatoria en general la relación electrónica con su Administración (art. 14.2.e) LPACAP) 82 , pero cuya concretización depende al final de las competencias organizativas y de personal de cada Administración, y de su plasmación en la correspondiente regulación reglamentaria de desarrollo y en las específicas convocatorias de que se trate.

Junto a ello, también se prevé en esta Disposición (¿como norma de agilización de los procesos selectivos?) que las convocatorias de estabilización publicadas puedan prever para aquellas personas que no superen el proceso su inclusión en bolsas de interinos específicas o su integración en bolsas ya existentes (de alcanzar, en su caso, la puntuación que se consideren suficiente).

\subsection{Otras previsiones complementarias}

Se cierra finalmente la norma que comentamos con dos últimas previsiones, relativas, de un lado, a la necesidad de elaboración anual de un informe de seguimiento de la situación de temporalidad en el empleo público por parte del Ministerio de Política Territorial y Función Pública (D. A. 2. ${ }^{a}$ ) y, con algo más de desarrollo, a las medidas a adoptar en concreto en el ámbito de la Administración local.

Al respecto, se señala que los municipios de régimen común pueden encomendar la gestión material de la selección de su personal funcionario de carrera o laboral fijo a las Diputaciones provinciales, cabildos, consejos insulares, entes supramunicipales u órgano equivalentes en las Comunidades Autónomas uniprovinciales (D. A. 1. ${ }^{a}$ ). La previsión tiene quizás más de recordatorio que de innovación/prescripción. El ejercicio de las competencias propias de los entes locales (en este caso, la gestión del personal) es susceptible, ya de por sí, de ejercicio propio o a través de las diferentes fórmulas de gestión cooperativa, dentro de ellas vía colaboración por parte de las Administraciones superiores (cuyo núcleo competencial gira en torno precisamente a los deberes de colaboración y asistencia interadministrativa). No ayuda sin embargo al correcto entendimiento del precepto el verbo utilizado («encomendar»), que, por un lado parece remitir a una sola posible vía de gestión cooperativa, y, por otro, resulta difícil de admitir desde las propias -y desiguales- posiciones institucionales de las Administraciones implicadas.

En párrafo aparte, también se señala que los municipios (hay que entender ya en este caso entonces, que «todos» los municipios), también podrán encomendar en los mismos términos la selección del personal funcionario interino y personal laboral temporal. Tampoco aquí no encontramos ante estrictas fórmulas de encomienda de gestión, y además, no se justifica la diferenciación de posibilidades según la naturaleza de los municipios.

También desde la obviedad máxima (salvo entendiendo que se trata de una fórmula de reforzamiento del cumplimiento de los trámites y plazos correspondientes y la evitación de las situaciones de dilación de la

82 Previsión generalizada ahora para la Administración General del Estado por la D. A. 1. a del RD 203/2021, de 30 de marzo, por el que se aprueba el Reglamento de actuación y funcionamiento del sector público por medios electrónicos. 
interinidad, aunque para ello hubiera sido necesario el establecimiento de un plazo obligatorio al respecto), se señala a continuación que «finalizado el proceso selectivo (local), la autoridad competente nombrará o contratará, según proceda, a los candidatos» que lo hayan superado.

$\mathrm{Y}$, finalmente, los procesos de estabilización de empleo temporal en el ámbito local también se regirán por lo dispuesto en el art. 2 de este RD-Ley 14/2021. Por tanto, no será de aplicación a los mismos lo dispuesto en los arts. 8 y 9 del RD 896/1991, de 7 de junio, por el que se establecen las reglas básicas y los programas mínimos a que debe ajustarse el procedimiento de selección de los funcionarios de Administración Local, es decir, que no se aplicarán en las entidades locales la exigencia de un número mínimo de temas en los programas selectivos y la obligatoriedad de una fase previa. No es difícil atisbar aquí, en una inaplicación ciertamente singular y restrictiva - de una norma que permanece vigente-, sólo a los procesos de estabilización de empleo temporal en el ámbito local que se rijan por el art. 2 del RD-Ley -y hasta donde llegue su vigencia-, un atisbo de clara desigualdad de trato en relación con el resto de procesos de estabilización existentes (los de las Leyes presupuestarias de 2017 y 2018 y cualesquiera Ofertas de Empleo Público ordinarias, incluida la del 2021 y las futuras $)^{83}$.

\section{FUTURO INMEDIATO PREVISIBLE Y VALORACIÓN CONJUNTA DEL PROCESO: ¿SE HA AVANZADO EN LA ADOPCIÓN DE MEDIDAS EFICACES, PROPORCIONADAS Y DISUASORIAS DE LA EXCESIVA TEMPORALIDAD EN EL EMPLEO PÚBLICO?}

Frente a la complejidad, estructuralidad e intensidad del problema, la solución parece apreciarse como insuficiente, desde un doble orden de provisionalidad.

De un lado, seguramente por no afrontar con decisión y de forma general la cuestión, que, como se ha dicho, no parece tanto de raíz normativa como de inteligencia organizativa y adecuada gestión (desde los mismos estadios decisionales de nivel político). En este sentido, nada puede asegurar, pese al claro reforzamiento positivo del carácter temporal de la relación de interinidad -desde el carácter básico de la regulación-, el cumplimiento efectivo, y en plazo, de las previsiones ahora añadidas en el art. 10 TREBEP (aunque es evidente que el problema -real- reside más bien en el proceso de estabilización del art. 2). Las medidas de responsabilidad y control no parecen suficientes, no ya sólo desde la perspectiva comunitaria de la funcionalidad -y no sólo disponibilidad- de un régimen «sancionador» eficaz, proporcionado y disuasorio, sino desde la propia óptica interna de la garantía efectiva de cumplimiento de las exigencias inherentes a la naturaleza necesariamente temporal y limitada del vínculo de empleo.

$Y$ de otro, y más grave, por la propia inestabilidad -por caducidad asumida- de la reforma.

Como se sabe, el RD-Ley 14/2021, de 6 de julio es una norma paradójicamente «temporal». Tras su entrada en vigor, y plena aplicabilidad en principio, y por distintos motivos (nucleados en torno al propio descontento de los distintos grupos de intereses implicados y su proyección política), se decidió en sede parlamentaria su tramitación como proyecto de Ley, tomando como inicio el 30 de agosto de 2021, aunque con retraso posterior en su tramitación al haberse prorrogado el plazo inicial de enmiendas ya en tres ocasiones $^{84}$.

Por tanto, no ya sólo que, por la profundidad -sustantiva y temporal- y enquistamiento de la cuestión no se tratara en su momento seguramente de un asunto de "extraordinaria y urgente» necesidad, como para justificar su -mínima y programática- regulación por Decreto-Ley, sino que, una vez aprobado éste, tras su convalidación, se ha acordado su tramitación como Ley que lo sustituirá de forma inminente -con mayor o menor modificación de sus previsiones-. Es evidente que la solución de fondo no ha gustado a nadie, ni desde el punto de vista de la plena satisfacción de sus aspiraciones por el personal interino ya existente ni desde la óptica complementaria del estricto ajustamiento a los principios constitucionales de una cuestión enormemente compleja. Pero junto a ello, lo objetivamente evidente es la inadecuación e incongruencia, determinantes de una denostable inseguridad jurídica, del legislador. A la relatividad positiva y falta efectiva de ajustamiento a las exigencias comunitarias se une, pues, la provisionalidad e incertidumbre de la regulación ${ }^{85}$.

83 En este sentido, Boltaina Bosch (2021).

84 En este sentido, se la ha calificado muy gráficamente como «norma fantasma», Boltaina Bosch (2021).

85 Y los propios y difíciles problemas de transitoriedad -y de incertidumbre sobre su mismo alcance- derivados, como bien pone ha puesto de manifiesto Boltaina Bosch (2021). 
A finales de octubre de 2021, la solución no se atisba cercana. La tramitación parlamentaria se encuentra aparentemente paralizada, entre-oscuras-negociaciones políticas y-publicitados-cruces de opiniones entre los colectivos implicados (lo que está dando pie, en la práctica, y de hecho, a una nueva paralización fáctica de los procesos selectivos, en espera «de acontecimientos»). Pero es evidente que la clave -y el gran problema de fondo- no es la regulación -más o menos adecuada a las exigencias comunitaria- del nuevo personal interino, sino el alcance de la estabilización o resarcimiento de la gran cantidad de interinos existentes. En este sentido, se esperaría la determinación inteligente, consensuada y equilibrada entre los límites de la posible flexibilidad a establecer en dicho proceso y el respeto escrupuloso de los principios constitucionales de acceso al empleo público y su -ya laxa- interpretación por el Tribunal Constitucional, sintonizando materialmente las exigencias comunitarias -no alejadas en teoría de la regulación positiva incluso anterior-, el reforzamiento -sí necesario- de los instrumentos de planificación, supervisión y control del cumplimiento efectivo de las normas y el resarcimiento proporcionado de los efectivos abusos producidos por un inadecuado aprovechamiento o fraude de una figura necesariamente causal y temporal, aunque necesaria, como es la del personal temporal de la Administración. ¿Será esto esperar -o desear- mucho?

\section{NOTA FINAL}

Dada la naturaleza también necesariamente «temporal» de este estudio -como la figura de empleados que trata-, conviene apuntar brevemente la situación en el momento de la corrección de pruebas del mismo (segunda semana de diciembre). El Proyecto de Ley de medidas urgentes para reducir la temporalidad en el empleo público se encuentra en el Senado. La novedad más importante introducida, y la más problemática, es la posibilidad, teóricamente excepcional, de que las Administraciones Públicas convoquen por el sistema de concurso aquellas plazas que, reuniendo los requisitos establecidos en el artículo 2.1, hubieran estado ocupadas con carácter temporal de forma ininterrumpida con anterioridad a 1 de enero de 2016 (D. A. 6. ${ }^{\text {a }}$. Adicionalmente, los procesos de estabilización contenidos en esta Disposición Adicional incluirán en sus convocatorias las plazas vacantes de naturaleza estructural ocupadas de forma temporal por personal con una relación, de esta naturaleza, anterior al 1 de enero de 2016 (D. A. 8. ${ }^{a}$ ). Dado el trámite legislativo pendiente, no parece que esta versión vaya a sufrir nuevas modificaciones. El uso excepcional, en estos casos, del sistema de concurso de méritos, desde su habilitación legal (art. 61.6 TREBEP) no parece discutible, al menos desde una estricta perspectiva jurídico-positiva (más allá de que por su propia naturaleza excepcional de acceso hubiera requerido -aunque se ha intentado- la explicitación de la motivación correspondiente, singularmente del tramo de años utilizado). Pero obviamente es una medida que no va a solucionar todos los problemas actuales de abuso de la temporalidad (menor de cinco años), que puede afectar indirectamente a otros posibles interesados en participar en los correspondientes procesos selectivos y que, por su necesaria concreción final en las convocatorias correspondientes -y sus bases reguladoras- en los diferentes niveles administrativos, seguramente va a desembocar en una progresiva conflictividad judicial.

\section{REFERENCIAS BIBLIOGRÁFICAS}

Alfonso Mellado, C. L. (2018). ¿Interino indefinido? Dos Sentencias de la Sala de lo Contencioso-Administrativo del Tribunal Supremo de 26 de septiembre de 2018. Revista de Derecho social, 84, 147-158.

Arrieta Idiakez, F. J. (2020). El empleo temporal en las Administraciones pública: límites, prevención y sanción a su utilización abusiva. Revista de Relaciones Laborales, 43, 41-72. https://doi.org/10.1387/lan-harremanak.21784

Barrachina Andrés, A. M. ${ }^{a}$ (2020). La Sentencia del TJUE de 19 de marzo de 2020 (fijeza de interinos) en clave local. Consultor de los ayuntamientos y de los juzgados, 7,85 y ss.

Boltaina Bosch, X. (2021). El Real Decreto-Ley 14/2021, sobre personal interino y estabilización: la compleja aplicación transitoria en la Administración Local. Revista digital CEMCI, 51. https://revista.cemci.org/numero-51/pdf/tribuna1-el-real-decreto-ley-14-2021-sobre-personal-interino-y-estabilizacion-la-compleja-aplicacion-transitoria-en-laadministracion-local.pdf.

Brufao Curiel, P. (2021). Funcionarios interinos y empleo público: análisis general de su controvertido régimen jurídico. Revista Vasca de Administración Pública, 120, 19-60. https://doi.org/10.47623/ivap-rvap.120.2021.01

Cabrera Rodríguez, J. (2020). Función pública temporal y precario administrativo. Revista Aragonesa de Administración Pública, 55, 392-415. 
Canal Fernández, L. (2019). ¿Y si los procesos de estabilización no fuera suficientes para hacer frente a las exigencias de la Directiva 1999/70? Al hilo de las conclusiones preliminares de los asuntos C-177/18, C-103/18 y C-429/18. Actualidad Administrativa, 12/2019.

Campos Daroca, J. M. (2017). Empleo público y fraude en la contratación temporal (p. 37 y ss.). Wolters Kluwer.

Cantero Martínez, J. (2017). El funcionario interino en la jurisprudencia: sobre la necesidad de repensar la figura. Revista Vasca de Gestión de Personas y Organizaciones Públicas, 12, 8-29. https://apps.euskadi.eus/z16-a5app2/ es/t59auUdaWar/R3/verArticulo?numejem=12\&tipo=R\&seccion=51\&correlativo=1\&contenido=5\&locale=es.

Cantero Martínez, J. (29 de julio de 2021). Los principios constitucionales rectores del empleo público no se negocian (a propósito de los interinos). Hay Derecho. https://www.hayderecho.com/2021/07/29/los-principiosconstitucionales-rectores-del-empleo-publico-no-se-negocian-a-proposito-de-los-interinos/

Carbonero Redondo, J. J. (2020). Consecuencias del abuso de la interinidad en el empleo público en la última jurisprudencia del TJUE. ¿Caben alternativas al artículo 10 del EBEP? Actualidad Administrativa, 5/2020.

Casas Baamonde, M. E. (2019). El fraude en la contratación temporal: su duración «inusualmente larga» (del contrato de interinidad para la cobertura de vacantes en el sector público y el plazo de tres años del artículo 70 del Estatuto Básico del Empleado Público). Revista de Jurisprudencia Laboral, 3/2019. https://www.boe.es/biblioteca_juridica/ anuarios_derecho/articulo.php?lang=es\&id=ANU-L-2019-00000000433

Casas Baamonde, M. E. y Ángel Quiroga, M. (2020). De nuevo la temporalidad del empleo en el sector público sujeto al Derecho administrativo. El cese de funcionaria interina sin indemnización no se opone al Derecho de la Unión Europea (Directiva 1999/70/CE). Revista de Jurisprudencia Laboral, 2/2020. https://www.boe.es/biblioteca juridica/anuarios_derecho/articulo.php?id=ANU-L-2020-00000000845

Castillo Blanco, F. (2020). Un sistema de empleo público distópico: ¿sería preciso reformar el EBEP? Documentación Administrativa, 7, 8-32. https://doi.org/10.24965/da.i7.10889

Castillo Blanco, F. A. (1995). Las problemáticas fronteras entre el Derecho Laboral y el Derecho Administrativo: a propósito de los contratos temporales en el sector público. Revista Española de Derecho Administrativo, 86, 187-218.

Cuenca Cervera, J. J. (2018). La temporalidad en el empleo público local: estrategias para su reducción tras el acuerdo para la mejora del empleo público. Revista Vasca de Gestión de Personas y Organizaciones Públicas, $12,54-67$. https://apps.euskadi.eus/z16-a5app2/es/t59auUdaWar/R3/verArticulo?numejem=12\&tipo=R\&seccion=52\&correlati $\mathrm{vo}=1 \&$ contenido $=1 \&$ locale $=$ es.

Esteban Miguel, A. (6 de octubre de 2021). La ausencia de adopción de medidas para evitar la excesiva temporalidad en las empresas públicas [entrada de blog]. Instituto de Derecho Local UAM. Recuperado de https://www.idluam. org/blog/la-ausencia-de-adopcion-de-medidas-para-evitar-la-excesiva-temporalidad-en-las-empresas-publicas/

Fernández Domínguez, J. J. (2020). El abuso en el nombramiento de personal estatutario interino: irregulares, pero no fijos: Comentario a la STJUE de 19 de marzo de 2020 (C-103/18 y C-429/18), asuntos Sánchez Ruiz y Fernández Álvarez. Revista de Estudios Jurídico Laborales y de Seguridad Social (REJLSS), 1, 166-176. https:// doi.org/10.24310/rejlss.vi1.10416

Fondevila Antolín, J. (2018). Acotaciones a la importante sentencia del Tribunal Supremo de 26 de septiembre de 2018: Se rechaza la figura del funcionario interino indefinido en el caso de nombramientos abusivos y la posibilidad de indemnización automática en caso de su cese (1). Consultor de los ayuntamientos y de los juzgados, 12/2018, 7280.

Fuentetaja Pastor, J. (2020a). El funcionario interino: entre la temporalidad y la estabilidad. Documentación Administrativa, 7, 88-103. https://doi.org/10.24965/da.i7.10892

Fuentetaja Pastor, J. (2020b). La conceptualización del funcionario interino. Anuario de la Función Pública, 5, 32-47. https://pe.ijeditores.com/pop.php?option=articulo\&Hash=4a09113831e1dc0bd6cf7ff1ca9ba54e.

Fuentetaja Pastor, J. (2020c), La utilización abusiva de los funcionarios interinos ante el derecho europeo: entre la transformación en funcionarios de carrera y el derecho a indemnización. Revista de Administración Pública, 212, 201-230. https://doi.org/10.18042/cepc/rap.212.07

Fuentetaja Pastor, J. (2019). «En cuanto sea adecuado a la naturaleza de su condición»: la convergencia de régimen jurídico entre funcionarios de carrera y funcionarios interinos. Revista Galega de Administración Pública, 1(58), 291-313. https://doi.org/10.36402/regap.v1i58.49

Fuentetaja Pastor, J. A. y Cantero Martínez, J. (dirs.) (2012). Crisis económica y función pública. Aranzadi.

Gordo González, L. (22 de noviembre de 2021). ¿Tiene fecha de caducidad la temporalidad en la Administración? (I): La insuficiente respuesta de los Tribunales. Recuperado de https://www.elforodelabos.es/el-acuerdo-con-losrepresentantes-de-los-trabajadores-blinda-la-modificacion-sustancial-de-las-condiciones-de-trabajo-pero-nosiempre-comentario-a-la-san-de-11-de-noviembe-de-2021/

Marín Alonso, I. (2017). El trabajador «indefinido no fijo» y condiciones de trabajo en régimen de interinidad. Trabajo y Derecho, 30, 34-55.

Martín de Arrate, S. (2021). Derechos del funcionario interino tras la publicación del Real Decreto-Ley 14/2021. El concepto «condiciones de trabajo». Diario La Ley, 9901.

Martín Muñoz, M. R. y Monereo Pérez, J. L. (2021). El abuso de la contratación temporal en el ámbito del sector público. Sentencia del TJUE de 11 de febrero de 2021 (asunto C-760/18). La Ley Unión Europea, 90. 
Mateos Martínez, J. (2020), El derecho a la no discriminación de los funcionarios interinos: estado de la cuestión tras la más reciente jurisprudencia comunitaria. Revista Vasca de Administración Pública, 117, 387-419. https://doi. org/10.47623/ivap-rvap.117.2020.09

Mauri i Majós, J. (2018). El acceso irregular a los empleos públicos. En J. Ponce Solé (coord.), Empleo público, derecho a una buena administración e integridad (pp. 41-96). Tirant lo Blanch.

Monereo Pérez, J. L. y Ortega Lozano, P. G. (2019). Interinidad e indemnización extintiva como problema: finalización de la relación laboral del interino por reincorporación del trabajador al que sustituye e inexistencia de indemnización. Revista de Jurisprudencia Laboral, 4/2019. https://www.boe.es/biblioteca_juridica/anuarios_ derecho/articulo.php?id=ANU-L-2019-00000000445

Moro Tella, R. (2021). La introducción de medidas legales para prevenir el abuso en la contratación temporal en el sector público: tarea inacabada para el legislador español. Actualidad Administrativa, 5/2021.

Morón Prieto, R. (12 de julio de 2021). Comentario urgente de las medidas dirigidas al control de la temporalidad laboral en el Acuerdo sobre el plan de choque para reducir la temporalidad en las Administraciones Públicas. NET21, 5. https://www.net21.org/comentario-urgente-de-las-medidas-dirigidas-al-control-de-la-temporalidadlaboral-en-el-acuerdo-sobre-el-plan-de-choque-para-reducir-la-temporalidad-en-las-administraciones-publicas/

Rodríguez Escanciano, S. (2020). Funcionario interino de larga duración: posibilidades y límites de estabilización. Revista de Jurisprudencia Laboral, 6/2020. https://www.boe.es/biblioteca_juridica/anuarios_derecho/articulo. php?id=ANU-L-2020-00000001034

Roqueta Buj, E. (2020). Los procesos de estabilización del empleo temporal en las Administraciones Públicas. Revista vLex de Derecho Administrativo, 1/2020, 9-45. https://vlex.es/vid/procesos-estabilizacion-empleotemporal-840323720

Sánchez Morón, M. (2020). Régimen jurídico de los funcionarios. Aranzadi.

Sánchez Morón, M. (2019). La consagración del funcionario interino indefinido. Revista de Administración Pública, 208, 223-238. https://doi.org/10.18042/cepc/rap.208.06

Sánchez Quiñones, L. (4 de junio de 2020). Dos lecturas de la decisión del TJUE sobre el personal interino reflejada en su Sentencia de 19 de marzo de 2020 (Asunto Fernández Álvarez y otros). Diario La Ley, 9647/2020. https:// diariolaley.laleynext.es/dll/2020/06/04/dos-lecturas-de-la-decision-del-tjue-sobre-el-personal-interino-reflejada-ensu-sentencia-de-19-de-marzo-de-2020-asunto-fernandez-alvarez-y-otros.

Suárez Corujo, B. (2017). El fraude en el trabajo de duración determinada en las Administraciones públicas españolas, según el Tribunal de Justicia de la Unión Europea. Revista Española de Derecho Europeo, 61, 153-185. http:// www.revistasmarcialpons.es/revistaespanoladerechoeuropeo/article/view/130_fraude_trabajo_duracion_ determinada_administraciones_publica.

Terradillos Ormaetxea, E. (2019). La nueva doctrina del TJUE sobre el contrato de interinidad en el empleo público, Temas Laborales. Temas laborales: Revista andaluza de trabajo y bienestar social, 146, 69-94.

Wade, H. y Forsyth, Ch. (2014). Administrative Law. Oxford University Press. https://doi.org/10.1093/ he/9780199683703.001.0001 